NASA

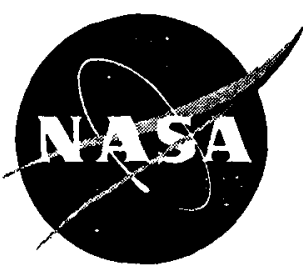

\title{
Launch Condition Deviations of Reusable Launch Vehicle Simulations in Exo-Atmospheric Zoom Climbs
}

Peter H. Urschel and Timothy H. Cox NASA Dryden Flight Research Center Edwards, California

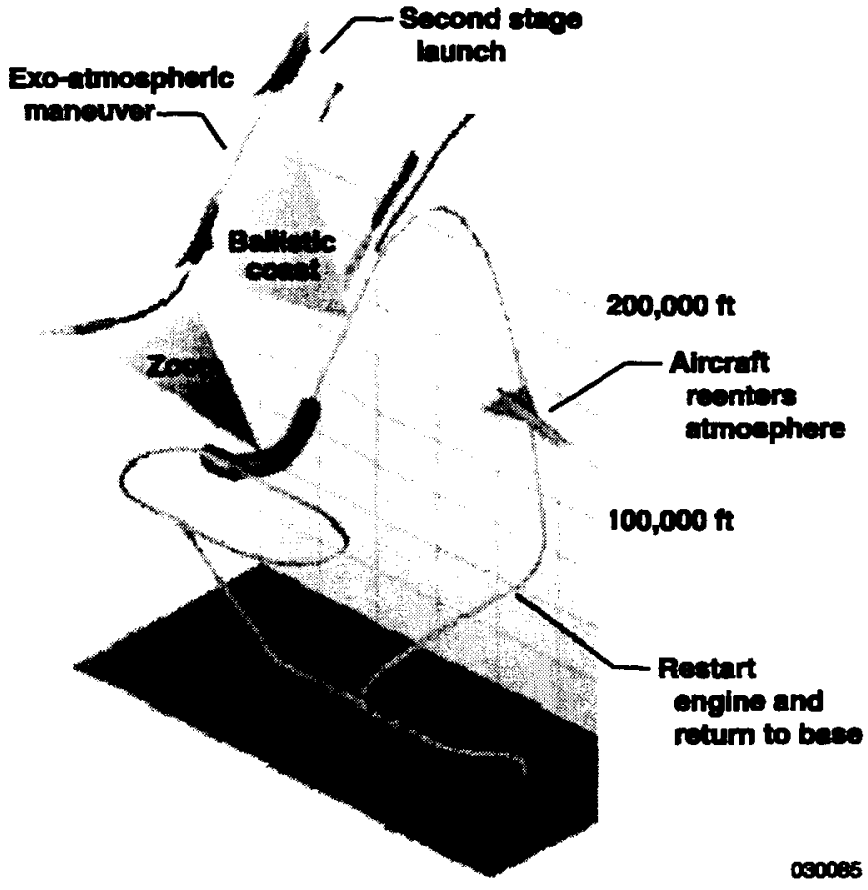




\section{The NASA STI Program Office...in Profile}

Since its founding, NASA has been dedicated to the advancement of aeronautics and space science. The NASA Scientific and Technical Information (STI) Program Office plays a key part in helping NASA maintain this important role.

The NASA STI Program Office is operated by Langley Research Center, the lead center for NASA's scientific and technical information. The NASA STI Program Office provides access to the NASA STI Database, the largest collection of aeronautical and space science STI in the world. The Program Office is also NASA's institutional mechanism for disseminating the results of its research and development activities. These results are published by NASA in the NASA STI Report Series, which includes the following report types:

- TECHNICAL PUBLICATION. Reports of completed research or a major significant phase of research that present the results of NASA programs and include extensive data or theoretical analysis. Includes compilations of significant scientific and technical data and information deemed to be of continuing reference value. NASA's counterpart of peer-reviewed formal professional papers but has less stringent limitations on manuscript length and extent of graphic presentations.

- TECHNICAL MEMORANDUM. Scientific and technical findings that are preliminary or of specialized interest, e.g., quick release reports, working papers, and bibliographies that contain minimal annotation. Does not contain extensive analysis.

- CONTRACTOR REPORT. Scientific and technical findings by NASA-sponsored contractors and grantees.
- CONFERENCE PUBLICATION.

Collected papers from scientific and technical conferences, symposia, seminars, or other meetings sponsored or cosponsored by NASA.

- SPECIAL PUBLICATION. Scientific, technical, or historical information from NASA programs, projects, and mission, often concerned with subjects having substantial public interest.

- TECHNICAL TRANSLATION. Englishlanguage translations of foreign scientific and technical material pertinent to NASA's mission.

Specialized services that complement the STI Program Office's diverse offerings include creating custom thesauri, building customized databases, organizing and publishing research results...even providing videos.

For more information about the NASA STI Program Office, see the following:

- Access the NASA STI Program Home Page at http://www.sti.nasa.gov

- E-mail your question via the Internet to help@sti.nasa.gov

- Fax your question to the NASA Access Help Desk at (301) 621-0134

- Telephone the NASA Access Help Desk at (301) 621-0390

- Write to: NASA Access Help Desk NASA Center for AeroSpace Information 7121 Standard Drive Hanover, MD 21076-1320 


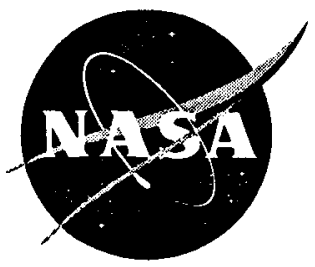

\section{Launch Condition Deviations of Reusable Launch Vehicle Simulations in Exo-Atmospheric Zoom Climbs}

Peter H. Urschel and Timothy H. Cox NASA Dryden Flight Research Center Edwards, California

National Aeronautics and

Space Administration

Dryden Flight Research Center

Edwards, California 93523-0273 


\section{NOTICE}

Use of trade names or names of manufacturers in this document does not constitute an official endorsement of such products or manufacturers, either expressed or implied, by the National Aeronautics and Space Administration.

Available from the following:

NASA Center for AeroSpace Information (CASI) 7121 Standard Drive

Hanover, MD 21076-1320

(301) 621-0390
National Technical Information Service (NTIS) 5285 Port Royal Road Springfield, VA 22161-2171

(703) $487-4650$ 


\begin{abstract}
The Defense Advanced Research Projects Agency has proposed a two-stage system to deliver a small payload to orbit. The proposal calls for an airplane to perform an exo-atmospheric zoom climb maneuver, from which a second-stage rocket is launched carrying the payload into orbit. The NASA Dryden Flight Research Center has conducted an in-house generic simulation study to determine how accurately a human-piloted airplane can deliver a second-stage rocket to a desired exo-atmospheric launch condition. A high-performance, fighter-type, fixed-base, real-time, pilot-in-the-loop airplane simulation has been modified to perform exo-atmospheric zoom climb maneuvers. Four research pilots tracked a reference trajectory in the presence of winds, initial offsets, and degraded engine thrust to a second-stage launch condition. These launch conditions have been compared to the reference launch condition to characterize the expected deviation. At each launch condition, a speed change was applied to the second-stage rocket to insert the payload onto a transfer orbit to the desired operational orbit. The most sensitive of the test cases was the degraded thrust case, yielding second-stage launch energies that were too low to achieve the radius of the desired operational orbit. The handling qualities of the airplane, as a first-stage vehicle, have also been investigated.
\end{abstract}

\title{
NOMENCLATURE
}

\section{Acronyms}

CHR Cooper-Harper rating

DARPA Defense Advanced Research Projects Agency

ELV expendable launch vehicle

HUD head-up display

ILS instrument landing system

MIPCC mass injection pre-compressor cooling

RASCAL Responsive Access, Small Cargo, and Affordable Launch

RCS reaction control system

RLV reusable launch vehicle

VVS velocity vector symbol

\section{Symbols}

$a$

semimajor axis length of operational orbit, $\mathrm{nmi}$

$C A P \quad$ control anticipation parameter, $g^{-1} \mathrm{sec}^{-2}$

$\mathrm{C}_{\mathrm{n}_{\beta}} \quad$ coefficient of yaw due to sideslip, per deg

$\mathrm{d} / \mathrm{dt} \quad$ time rate of change (first derivative with respect to time) 
eccentricity

g

gravitational acceleration

$H \quad$ altitude, $\mathrm{ft}$

inclination of the operational orbit, deg

$\mathrm{J}_{2} \quad$ geopotential coefficient

$\mathrm{K}_{\mathrm{ctrk}}$ gain on crosstrack error

$\mathrm{K}_{\text {ctrkrt }}$ gain on crosstrack rate

$\mathrm{K}_{\mathrm{H}} \quad$ gain on altitude error

$\mathrm{K}_{\text {hor }}$ gain on horizontal needle

$K_{\text {vert }} \quad$ gain on vertical needle

$\mathrm{K} \alpha \quad$ gain on angle-of-attack error

$\mathrm{K} \theta$ gain on pitch attitude error

$\mathrm{K} \phi \quad$ gain on bank angle error

M Mach number

$\bar{q} \quad$ dynamic pressure, $\mathrm{lb} / \mathrm{ft}^{2}$

$R_{\text {lnch }} \quad$ geocentric radius of launch condition, $\mathrm{nmi}$

$R_{\text {op }} \quad$ geocentric radius of operational orbit, $\mathrm{nmi}$

$R_{\oplus} \quad$ Earth's equatorial radius, nmi

TC azimuth of the launch condition in the rotating Earth reference frame (true course), deg

UT universal time, sec

$V \quad$ true airspeed, $\mathrm{ft} / \mathrm{sec}$

$V_{\mathrm{i}} \quad$ geocentric, inertial reference frame launch speed, $\mathrm{nmi} / \mathrm{sec}$

$V_{\mathrm{ix}} \quad$ horizontal component of geocentric, inertial speed, $\mathrm{nmi} / \mathrm{sec}$

$V_{\mathrm{iy}} \quad$ vertical component of geocentric, inertial speed, $\mathrm{nmi} / \mathrm{sec}$

$V_{\text {op }} \quad$ geocentric speed required to be on circular operational orbit, $\mathrm{nmi} / \mathrm{sec}$

$V_{\text {sound }} \quad$ speed of sound, $\mathrm{ft} / \mathrm{sec}$

$V_{\mathrm{T}} \quad$ geocentric transfer orbit speed at launch point (inertial frame), $\mathrm{nmi} / \mathrm{sec}$

$\alpha \quad$ angle of attack, deg

$\beta \quad$ angle of sideslip, deg

$\gamma \quad$ flightpath angle in rotating Earth reference frame, deg 
$\gamma_{i} \quad$ launch flightpath angle in nonrotating geocentric inertial frame, deg

$\gamma_{0} \quad$ flighpath angle on operational orbit, deg

$\gamma_{\text {op }} \quad$ flightpath angle on circular operational orbit, deg

$\Delta \quad$ change in a parameter

$\Delta V_{\mathrm{pc}} \quad$ geocentric speed change required to complete a plane change maneuver, $\mathrm{nmi} / \mathrm{sec}$

$\Delta V_{\text {tot }} \quad$ total geocentric speed change required to insert ELV onto transfer orbit and onto operational orbit, $\mathrm{nmi} / \mathrm{sec}$ (i.e., $\Delta V_{\text {tot }}=\Delta V_{1}+\Delta V_{2}$ )

$\Delta V_{1} \quad$ speed change required to insert ELV onto transfer orbit from launch flight condition, $\mathrm{nmi} / \mathrm{sec}$

$\Delta V_{2} \quad$ speed change required to insert ELV onto operational orbit from transfer orbit, $\mathrm{nmi} / \mathrm{sec}$

$\boldsymbol{\varepsilon}$ specific mechanical energy of the transfer orbit, $\mathrm{nmi}^{2} / \mathrm{sec}^{2}$

$\eta \quad$ auxiliary angle, deg

$\theta \quad$ pitch attitude, deg

l longitude of launch condition, deg

$\lambda_{\mathrm{gc}}$ geocentric latitude of the launch condition, deg

$\mu_{\oplus} \quad$ gravitational parameter of Earth

$\tau_{\mathrm{GST}} \quad$ Greenwich sidereal time, sec

$\tau_{\mathrm{GST0}} \quad$ Greenwich sidereal time at zero hours on launch day, sec

$\phi \quad$ bank angle, deg

$\chi \quad$ specific angular momentum of the transfer orbit, $\mathrm{nmi}^{2} / \mathrm{sec}$

$\psi \quad$ inertial launch azimuth measured from true north, deg

$\omega_{\oplus} \quad$ Earth's rotational rate, $\mathrm{rad} / \mathrm{sec}$

$\Omega \quad$ longitude of the ascending node, deg

\section{INTRODUCTION}

Reliable, flexible, and low-cost access to space is becoming increasingly important for both commercial and military programs. Although many dedicated, flight-proven launch vehicles are currently available, a gap exists in the dedicated launch capability for payloads less than $220 \mathrm{lb}$. Current trends indicate that payload size is decreasing and potential uses of low Earth orbit satellite constellations are being evaluated, thereby increasing the need for dedicated launch capability for payloads less than $220 \mathrm{lb}$. ${ }^{1}$ 
Most launch vehicle systems are optimized for payloads much larger than $220 \mathrm{lb}$. They require large teams of highly trained personnel, dedicated launch ranges, and, with the exception of Sea Launch (Sea Launch Company, LLC, Long Beach, California) and the air-launched Pegasus ${ }^{\circledR}$ (Orbital Sciences Corporation, Dulles, Virginia), large and complex land-based launch facilities. They also have lengthy prelaunch payload processing and launch vehicle integration flows, and have launch windows that are limited by the fixed geographic location of the launch site on the surface of the Earth (with the exception of Pegasus). Additionally, because payloads less than $220 \mathrm{lb}$ must be launched into orbit by means of piggybacking onto larger payloads available on current launch vehicles, the orbit injection requirements of the larger payload generally take precedence over those of the smaller payload, thereby restricting or eliminating access to the desired operational orbit.

The Responsive Access, Small Cargo, and Affordable Launch (RASCAL) demonstration program, sponsored by the Defense Advanced Research Projects Agency (DARPA), seeks to provide a solution to the problem of reliable, flexible, and low-cost access to space for payloads less than $220 \mathrm{lb}$. The RASCAL concept ${ }^{1}$ uses an aircraft as the first stage of a launch vehicle system, known as the reusable launch vehicle (RLV), with an expendable rocket vehicle comprising the remaining stages, known as the expendable launch vehicle (ELV). The payload is attached to the ELV, which is carried aloft to the launch flight condition by the RLV. Figure 1 illustrates the RASCAL concept. ${ }^{1}$ The RASCAL goal for the ELV launch flight condition from the RLV is a dynamic pressure, $\bar{q}$, of $1 \mathrm{lb} / \mathrm{ft}^{2}$.

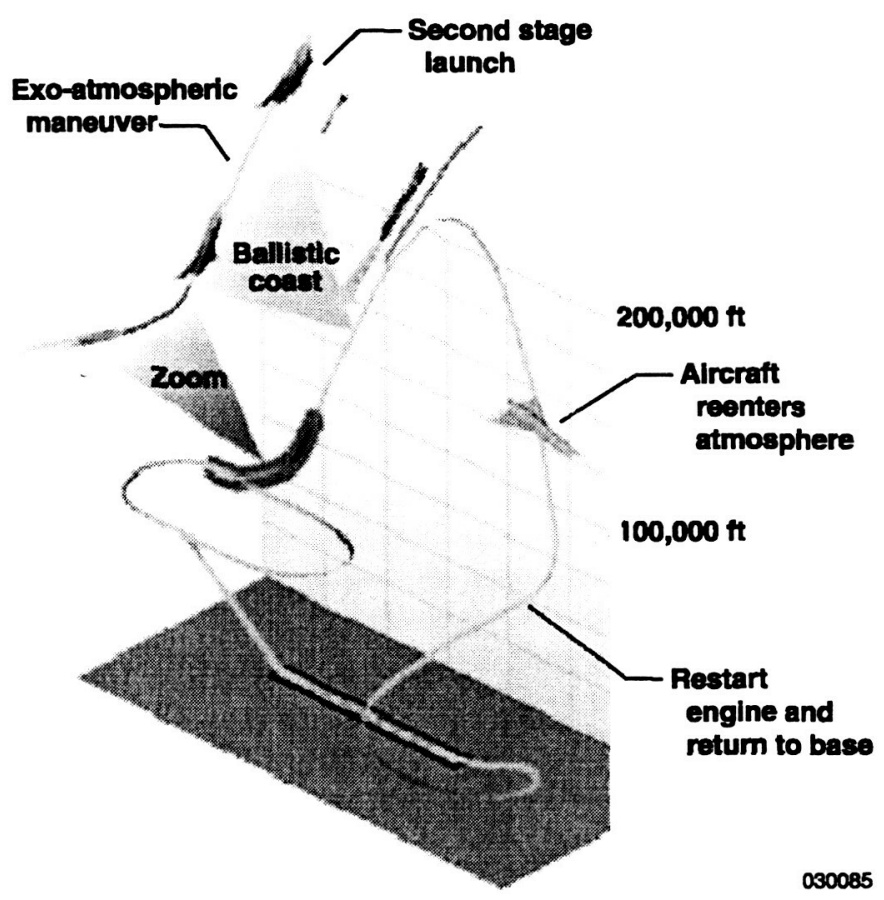

Figure 1. Responsive Access, Small Cargo, and Affordable Launch concept. ${ }^{1}$ 
The following is a direct quote from reference 1:

Aircraft operations are a good example of operations that are flexible and adaptable towards evolving and emerging missions. Aircraft operations are also affordable, in part, because an extensive and highly developed infrastructure and technology base exist. The development of a successful RASCAL system will use aircraft operations as a strong influence in its concept of operations and will take as much advantage as possible of existing aircraft infrastructure and technology.

Based on this assessment, DARPA has proposed an extension of military aircraft operations for the RLV to meet the following objectives:

1. Demonstrate mission turnaround time within a 24-hour period after payload arrival (at RLV sortie point of origin)

2. Deliver a 165 -lb payload into a 270 -nmi (altitude) sun synchronous orbit

3. Demonstrate, through a credible cost estimating model, that recurring launch costs can converge on the goal of $\$ 750,000$ per launch of a 165 -lb payload for the RASCAL operating system (not including the cost of the satellite payload)

4. Validate the ability to operate from an 8200 -ft runway with minimal peculiar support equipment, independent of test ranges for telemetry and tracking support

5. Demonstrate mission scramble capability within 1 hour of notification, after ELV integration

6. Demonstrate the ability to loiter and adjust the flightpath to accommodate dynamic mission planning

Additionally, the RASCAL concept requires that the RLV achieve the launch flight condition by means of conventional airbreathing jet engines, without the use of rocket engines. For the RLV to achieve the desired ELV launch flight condition without the use of rocket engines, the RASCAL concept calls for the development of mass injection pre-compressor cooling (MIPCC) systems for use with conventional jet engines. The MIPCC systems provide thrust augmentation and extended engine operation into flight regimes beyond the operating envelope of conventional airbreathing engines.

Few research efforts have employed a concept similar to that of the RASCAL program. Of all previous research programs, the X-15 and NF-104 programs ${ }^{2}$ are the most similar (conceptually) to RASCAL. The X-15 aircraft reached altitudes exceeding $350,000 \mathrm{ft}$ and apogee speeds of approximately $4500 \mathrm{ft} / \mathrm{sec}^{3}{ }^{3}$ necessitating piloting techniques and guidance and control strategies ${ }^{4,5}$ similar to those required by RASCAL. Significant differences exist, however, between the RASCAL requirements and those upon which the X-15 aircraft was designed, built, and operated. One of the main differences is that the RASCAL RLV must carry an ELV to a tightly constrained launch flight condition, at which time the ELV separates from the RLV and ignites its own rocket engine(s) for insertion of the satellite payload into orbit.

The NASA Dryden Flight Research Center (Edwards, California) has participated in the RASCAL phase I program and performed a generic RASCAL simulation study. The main objectives of the study were to quantify deviations expected in the ELV launch condition and examine how these deviations propagate through the subsequent ELV transfer orbit. Consistent with the RASCAL concept, a real-time, fixed-base, pilot-in-the-loop simulation of a fighter aircraft, complete with pilot controls and external visual imagery, was modified and used as a generic RLV. A reference zoom climb maneuver, consistent with DARPA objectives, was generated ad hoc and implemented into the simulation to drive guidance 
displays. Four NASA Dryden research pilots flew the simulation and tracked the reference trajectory to document the ELV launch condition deviations from the reference launch condition. In addition to the nominal case, the pilots tracked the reference trajectory in the presence of winds, with reduced thrust, and with initial condition offsets at the start of the maneuver. Handling qualities and guidance display concepts, which are significant factors in the pilot's ability to track the reference trajectory, have been documented and discussed. Although an autopilot probably would be used to fly this type of maneuver, the use of a human pilot-in-the-loop simulation has facilitated insight into the design of the maneuver, facilitated the identification of problems in the dynamics during the maneuver, and utilized the human pilot's inherent adaptability and insight to more efficiently develop the guidance concept. Under the assumption that an autopilot can track more precisely than a human pilot can, this process should result in a worst-case set of ELV launch deviations. A conceptual ELV transfer orbit was developed, and the launch conditions from each trajectory have been applied to examine the effects on the final ELV orbital state. Correlations between the ELV launch condition and the final ELV orbital states have been made, and the most sensitive launch condition parameters have been identified. The objective of these data is to provide insight to those who must design the size of the ELV to account for ELV launch and transfer orbit errors.

\section{TEST SETUP}

This section discusses the setup for the test simulation. The aircraft, simulation facility, reference RLV trajectory, pilot guidance and display, wind profile variations, and ELV transfer orbit are described in detail.

\section{Aircraft}

A fighter-type aircraft was chosen for use as the RLV in this study. This aircraft, with the addition of MIPCC augmentation, best represents the capabilities required by the RASCAL RLV concept. It is a high-performance, twin-engine, tactical jet fighter airplane with a maximum design Mach number of 2.5 without MIPCC. It possesses the airframe geometric configuration, area, and payload capability required to carry an ELV-class payload. Another factor for choosing this aircraft is the availability of a real-time, pilot-in-the-loop simulation capability.

The aircraft is controlled by stabilators, which are symmetrically and differentially deflected, ailerons, and rudders. A control augmentation system drives the surfaces, using rates, accelerations, and angle-of-attack feedbacks. With the control augmentation system active, the control system provides normal acceleration command in the pitch axis and roll rate in the lateral axis.

\section{Simulation Facility}

The NASA Dryden simulation facility (fig. 2) is a fixed-base, real-time, pilot-in-the-loop, six-degree-of- freedom simulation with a standard stick and rudder pedal for pilot controls, head-up display (HUD) and cockpit flight instruments, and external real-time visual imagery. Oblate Earth nonlinear equations of motion are used. High-fidelity propulsion and aerodynamic models were also implemented and considered valid to Mach 2.5 and altitudes of $70,000 \mathrm{ft}$. For the RASCAL study, modifications to the simulation included the implementation of a reaction control system (RCS); 
an extension of the aerodynamic model in Mach number and altitude; the implementation of a simple MIPCC thrust augmentation model; the development of a guidance algorithm that generates commands to instrument landing system (ILS) type needles; and fine-tuning of the control system. These modifications, discussed in detail in the remainder of this section, were considered reasonable estimates based on the conceptual nature of the study.

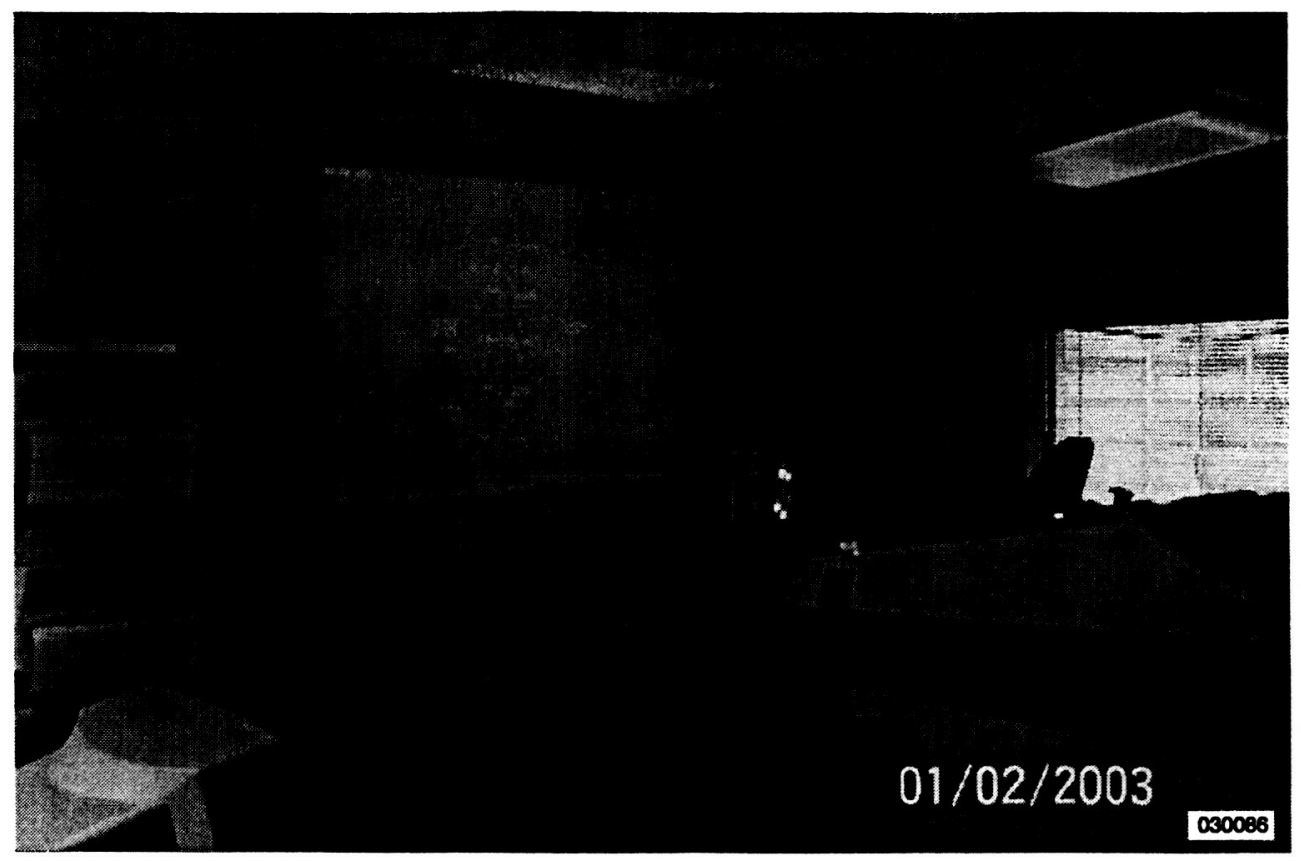

Figure 2. The NASA Dryden simulation facility.

\section{RCS Design and Flight Control System Modification}

The RCS has been designed to be similar to the proportional, rate command system of the X-15 aircraft. ${ }^{6,7}$ Dead bands were used on the error signals and stick position but were not fine-tuned for fuel usage or to minimize rocket fire time. A set of pitch and yaw thrusters were modeled on the nose and the tail of the aircraft, and a set of roll axis thrusters were modeled on each wingtip. As shown in figure 3, the same stick and rudder pedals used for atmospheric flight were used to activate the RCS in exo-atmospheric flight. For dynamic pressure greater than $200 \mathrm{lb} / \mathrm{ft}^{2}$, pure aerodynamic control was used. For dynamic pressure less than $200 \mathrm{lb} / \mathrm{ft}^{2}$, the RCS switched on to supplement the aerodynamic control. For dynamic pressure less than $40 \mathrm{lb} / \mathrm{ft}^{2}$, the control surfaces were frozen and control was exclusively maintained by the RCS. These dynamic pressure values were not optimal but were chosen to avoid potential handling qualities problems during the zoom climb. Table 1 lists the inertias and thruster size and shows that the resultant maximum acceleration compares well to that of the X-15 design.

Initial investigations revealed that the aircraft exhibited a wallowing characteristic as it entered the upper end of the atmosphere during the zoom climb. This wallowing characteristic was traced to a reduction in damping during the climb in all three axes. During this portion of the flight, the dimensional damping derivatives, a function of $\bar{q} / V$, decreased by a factor of 10 because of a rapid decrease in dynamic pressure. To provide increased aerodynamic damping, rate feedback gains in the control system were ramped from the nominal gain at the start of the pullup to a factor of 10 according to dynamic pressure variation. Stability was validated through the pilot-in-the-loop simulation, and robustness of the control laws was not analyzed. 


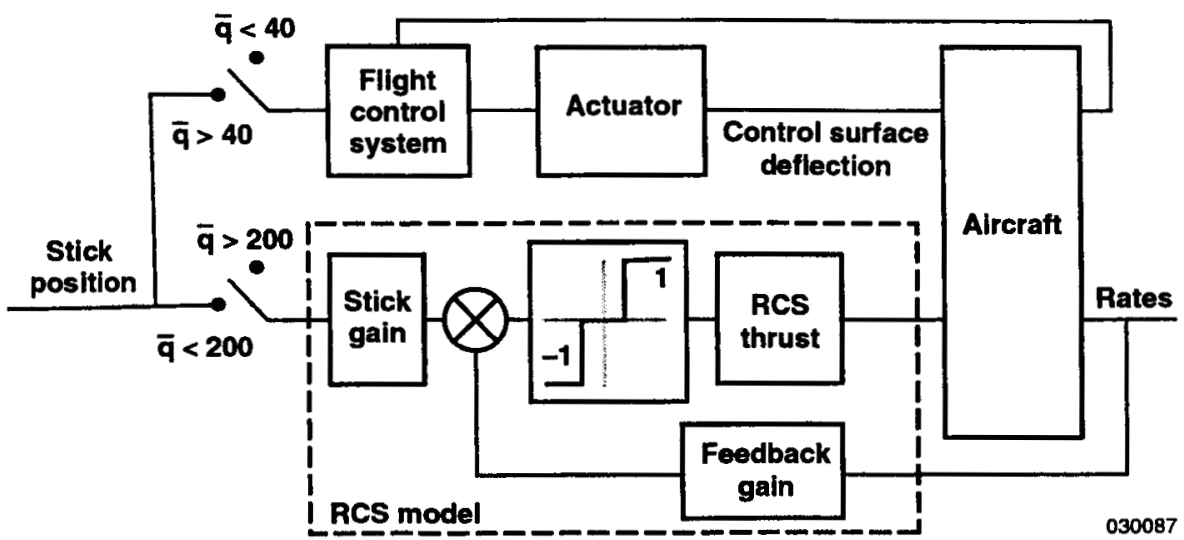

Figure 3. Reaction control system and aerodynamic flight control scheme.

Table 1. RCS values and comparison of maximum acceleration with $\mathrm{X}-15$ data.

\begin{tabular}{ccccc}
\hline \hline Axis & $\begin{array}{c}\text { Inertia } \\
(\text { slugs } \\
\left.\cdot \mathrm{ft}^{2}\right)\end{array}$ & $\begin{array}{c}\text { Thruster } \\
\text { Size } \\
(\mathrm{lb})\end{array}$ & $\begin{array}{c}\text { Maximum } \\
\text { Acceleration } \\
\left(\mathrm{deg} / \mathrm{sec}^{2}\right)\end{array}$ & $\begin{array}{c}\text { X-15 Maximum } \\
\text { Acceleration } \\
\left(\mathrm{deg} / \mathrm{sec}^{2}\right)\end{array}$ \\
\hline Pitch & 187,000 & 150 & 2.57 & 2.5 \\
Roll & 29,900 & 100 & 6.51 & 5.0 \\
Yaw & 212,200 & 150 & 2.27 & 2.5 \\
\hline \hline
\end{tabular}

\section{Extended Aerodynamics}

The RLV aircraft aerodynamic database was extended to Mach 5, based on trends in flight test data from other high-speed aircraft valid to Mach 3.0, and trends in aerodynamic estimates from research conducted in support of a particular RLV design through the RASCAL program. For supersonic conditions, these estimates were generated with a constant-pressure panel method, consisting of nonplanar, noninclined panels with linearized boundary conditions. Figure 4 illustrates how the coefficient of yaw due to sideslip, $C_{n_{\beta}}$, was extended by comparison with the panel code estimate. The application of these trends revealed the need for additional directional stability for the RLV at high Mach numbers. An increment to the extended $C_{n_{\beta}}$, based on the panel code estimates of ventral fins and a 25-percent increased vertical tail size (see figure 4), was added to the simulation to provide the required stability. A hold-last-value technique was applied to extend the database for high altitudes. 


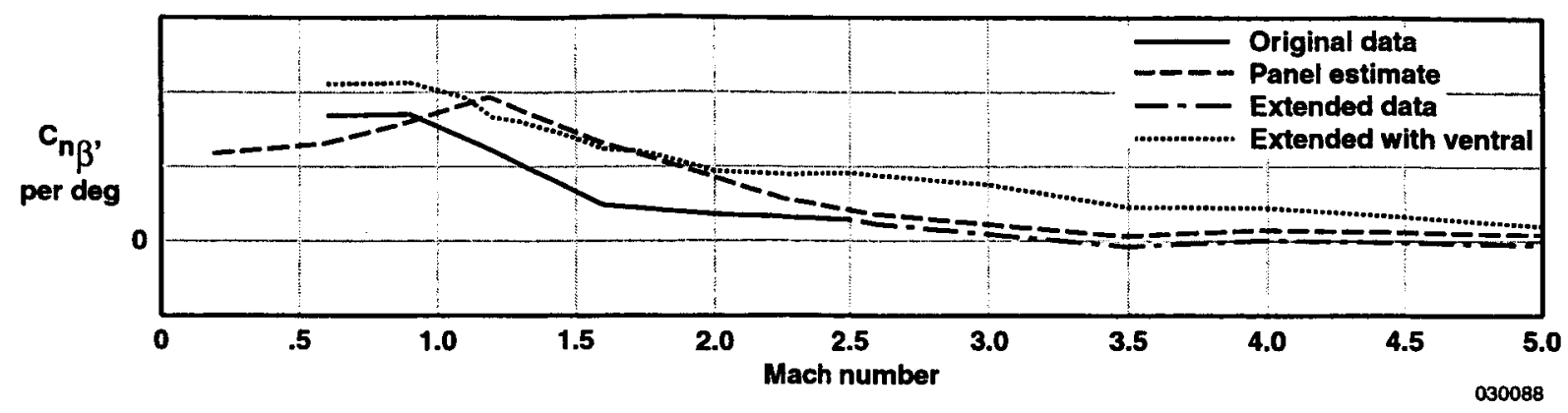

Figure 4. Extended aerodynamics using $C_{n_{\beta}}$.

\section{MIPCC Model}

Figure 5 presents a simplified diagram of the MIPCC concept envisioned for this study. Liquid oxygen and water are injected into the airstream in front of the compressor, causing lower airstream temperatures, which increase the mass flow rate through the engine. The reaction of additional fuel and the injected oxygen provides additional thrust augmentation and allows the engine to operate at altitudes higher than normal. The MIPCC thrust augmentation was implemented in the simulation as a user-defined multiplier on the unaugmented net thrust. A multiplier of 2 was nominally used for this study. Although a multiplier of 2 represents a significantly large increase in thrust, some studies have shown that high thrust is potentially achievable. ${ }^{8}$ Thrust was instantaneously cut off when $\bar{q}$ became less than $80 \mathrm{lb} / \mathrm{ft}^{2}$ during the climb portion of the maneuver.

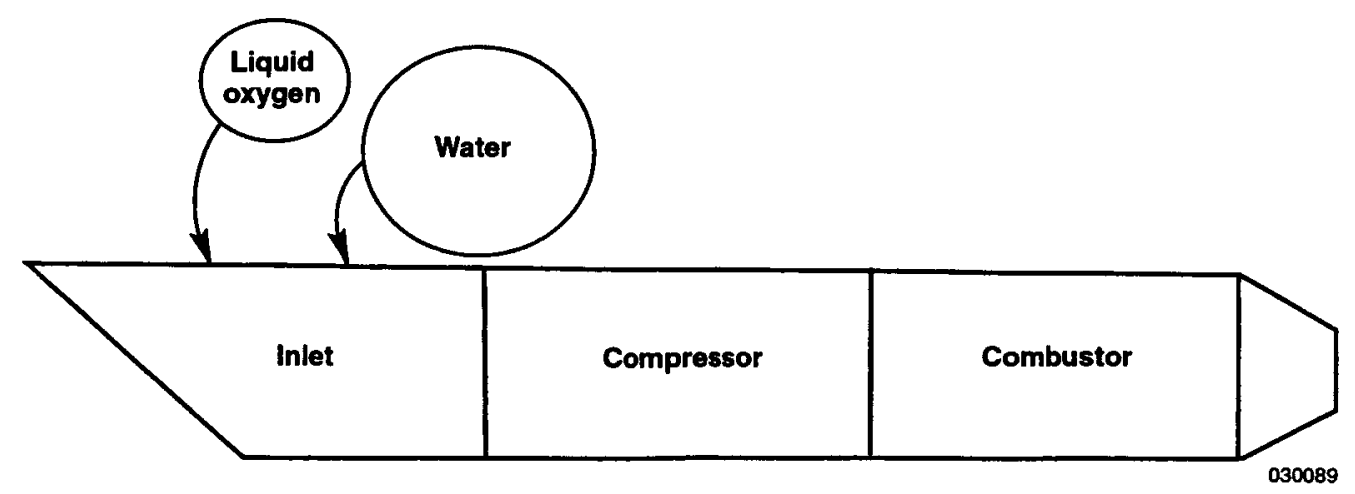

Figure 5. Mass injection pre-compressor cooling concept. 


\section{Control Power Modification}

Initial trajectory investigations indicated the control power of the original RLV configuration was marginally acceptable, and the stick occasionally was reaching the aft limit. A 20-percent increase in the deflection of the stabilators and a 1-in. increase in aft stick deflection corrected this problem. A slight reduction in the force gradient of the stick allowed stick force per $g$ to remain the same as the original configuration.

\section{Reference RLV Trajectory}

The design operational orbit was assumed to be a geocentric, circular, 270-nmi altitude, sun synchronous orbit. To satisfy ELV launch condition requirements imposed by this operational orbit, a reference RLV zoom climb trajectory (fig. 6) was determined ad hoc by conducting multiple pilot-in-the-loop engineering simulations. The RLV reference trajectory was a no-wind, level acceleration at $40,000 \mathrm{ft}$ from Mach 0.8 to approximately Mach 3.2, followed by a 3.5-g wings-level pullup to a pitch attitude, $\theta$, of $55^{\circ}$. This pitch attitude was maintained while the RCS came on, the engines shut down, and the vehicle exited the aerodynamically usable atmosphere. At this atmospheric exit point, aerodynamic control was no longer significant and the RLV was considered to be ballistic, with only rotational control possible about the RLV center of gravity. Thus the RLV trajectory could no longer be adjusted prior to the ELV launch condition. All trajectory corrections, therefore, had to be made before the RLV became ballistic, and any error rates that existed at the point of becoming ballistic determined the final magnitude of the ELV launch condition errors. When an angle of attack, $\alpha$, of $20^{\circ}$ was first reached during the climb (which occurred at some point after capturing a pitch attitude of $55^{\circ}$ ), it was maintained throughout the ballistic arc and initial reentry into the lower atmosphere, while holding an angle of sideslip, $\beta$, of $0^{\circ}$. Similar guidance strategies were used for high-altitude runs in the X-15 program. The ELV launch flight condition was defined to occur when $\bar{q}$ equaled $1 \mathrm{lb} / \mathrm{ft}^{2}$. Maximum RLV altitude was greater than $200,000 \mathrm{ft}$. This simulated RLV nominal trajectory did not extend beyond the initial reentry into the lower atmosphere.

The nominal no-wind reference RLV zoom climb trajectory was recorded and became the baseline to which all subsequent runs were compared for determining launch condition errors. Table 2 lists the principal launch condition parameters and defines the launch condition for the reference trajectory, consistent with RASCAL program objectives.

The launch occurs near the U.S. West Coast, in the vicinity of Los Angeles, California. The location was chosen ad hoc and operational constraints were not addressed. 


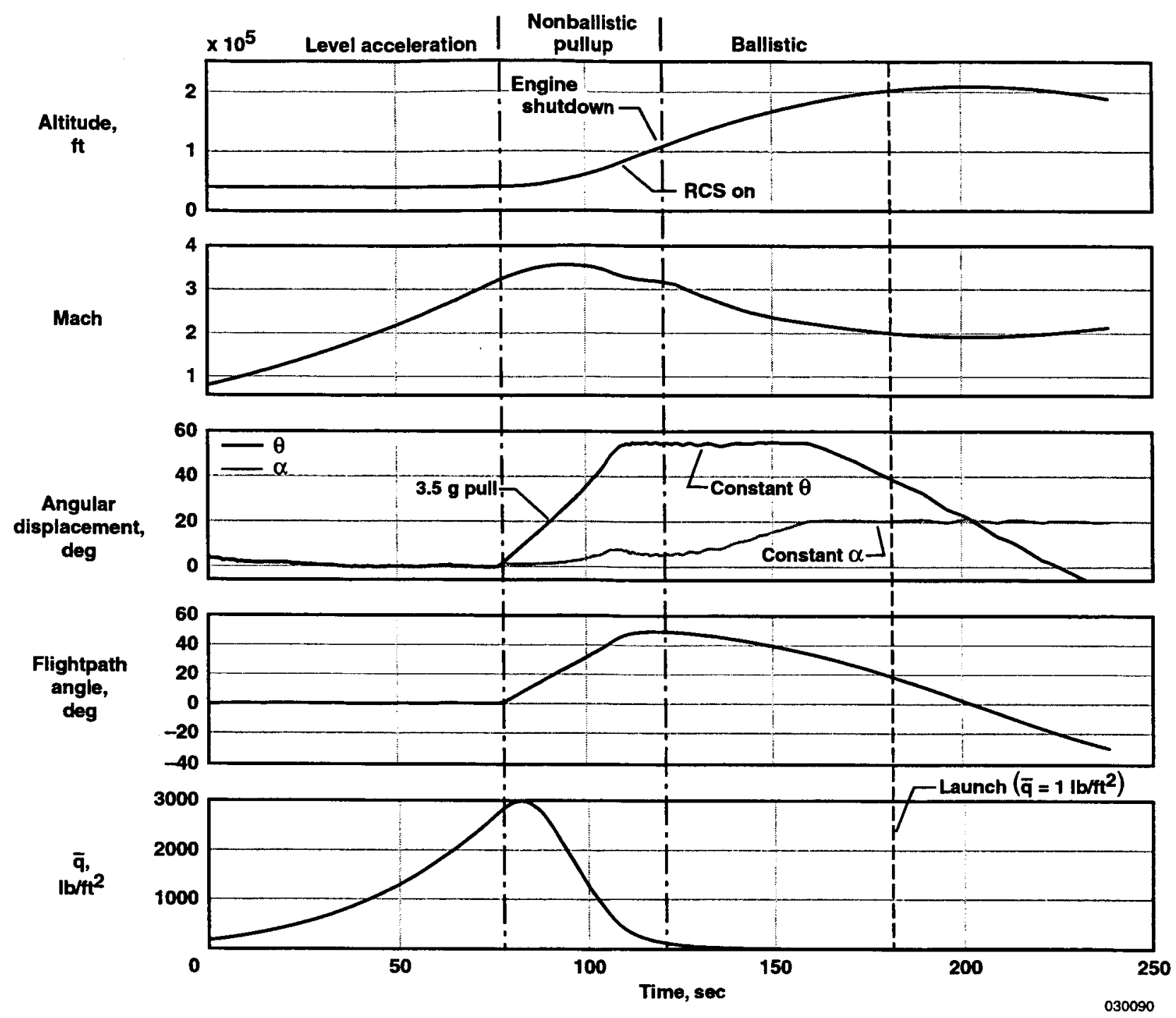

Figure 6. Reference trajectory.

Table 2. Launch condition for the reference trajectory.

\begin{tabular}{lc}
\hline \multicolumn{1}{c}{ Parameter } & Value \\
\hline Altitude, $H$ & $202,760 \mathrm{ft}$ \\
Mach number, $\mathrm{M}$ & 2.00 \\
Time from start of level acceleration & $181.9 \mathrm{sec}$ \\
Flightpath angle, $\gamma$ & $18.2^{\circ}$ \\
Inertial launch, azimuth, $\Psi$ & $188.8^{\circ}$ \\
Geocentric latitude, $\lambda_{\mathrm{gc}}$ & $34.0^{\circ}$ \\
Longitude, $\mathrm{l}$ & $-118.9^{\circ}$ \\
\hline \hline
\end{tabular}




\section{Pilot Guidance and Display}

Multiple conditions of altitude, north and east components of translation, and pitch attitude were chosen as a function of the range along the reference trajectory and implemented in the simulation as a guidance trajectory for the pilots to follow (fig. 7). A set of HUD horizontal and vertical needles (fig. 8), which were referenced to a velocity vector symbol (VVS) or flightpath marker on the HUD, were provided as steering cues to the guidance trajectory. These HUD needles were similar to conventional ILS needles used for ILS instrument approaches.

The guidance equations used to drive the needles are as follows:

$$
\begin{aligned}
& \text { Horizontal needle }=\mathrm{K}_{\text {hor }}\left(\mathrm{K}_{\mathrm{H}} \times \Delta \mathrm{H}+\mathrm{K}_{\alpha} \times \Delta \alpha+\mathrm{K}_{\theta} \times \Delta \theta\right) \\
& \text { Vertical needle }=\mathrm{K}_{\text {vert }}\left(\mathrm{K}_{\mathrm{ctrk}} \times \text { crosstrack }+\mathrm{K}_{\text {ctrkrt }} \times \mathrm{d}(\operatorname{crosstrack}) / \mathrm{dt}+\mathrm{K}_{\phi} \times \Delta \phi\right)
\end{aligned}
$$
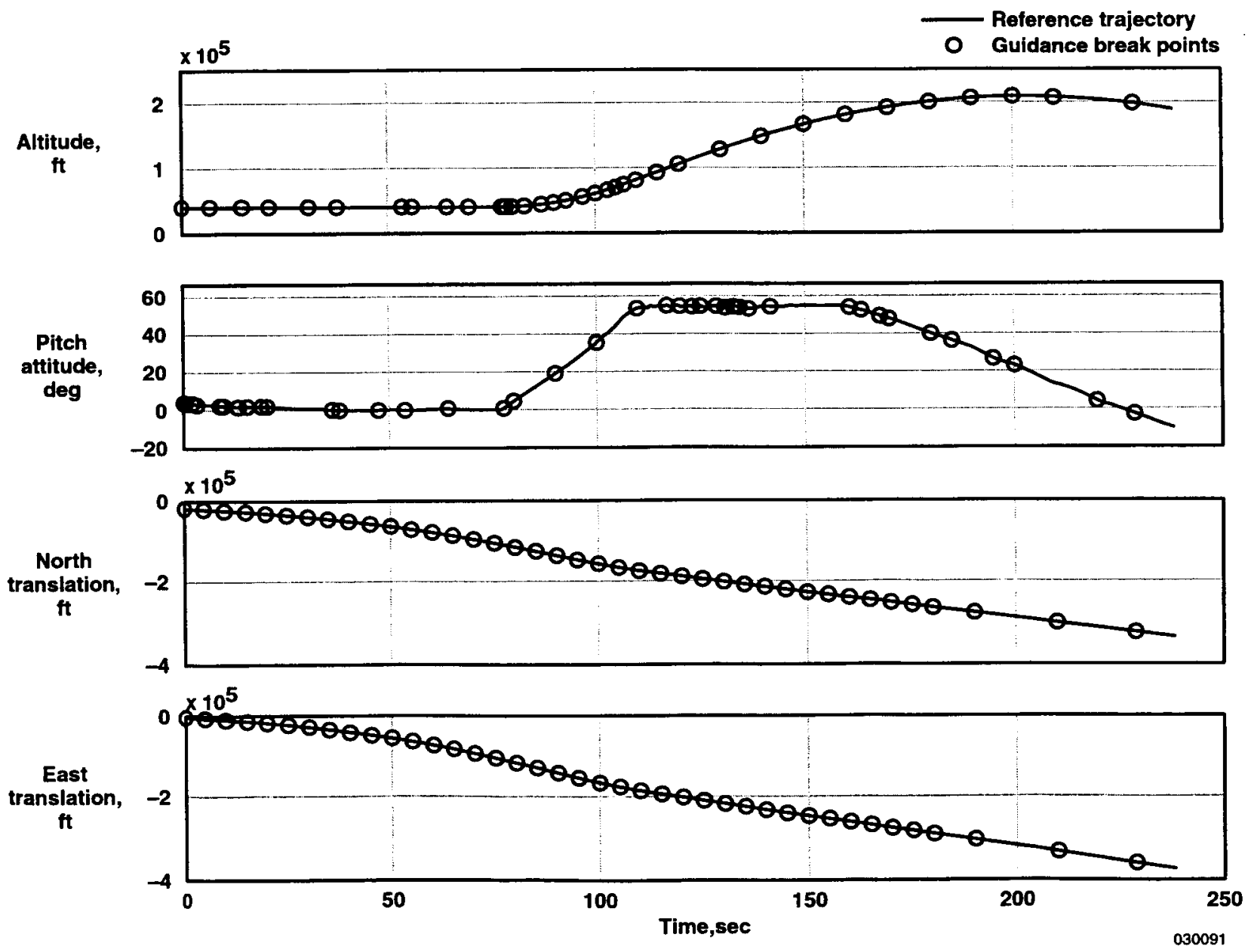

Figure 7. Break points used by guidance tables in simulation. 


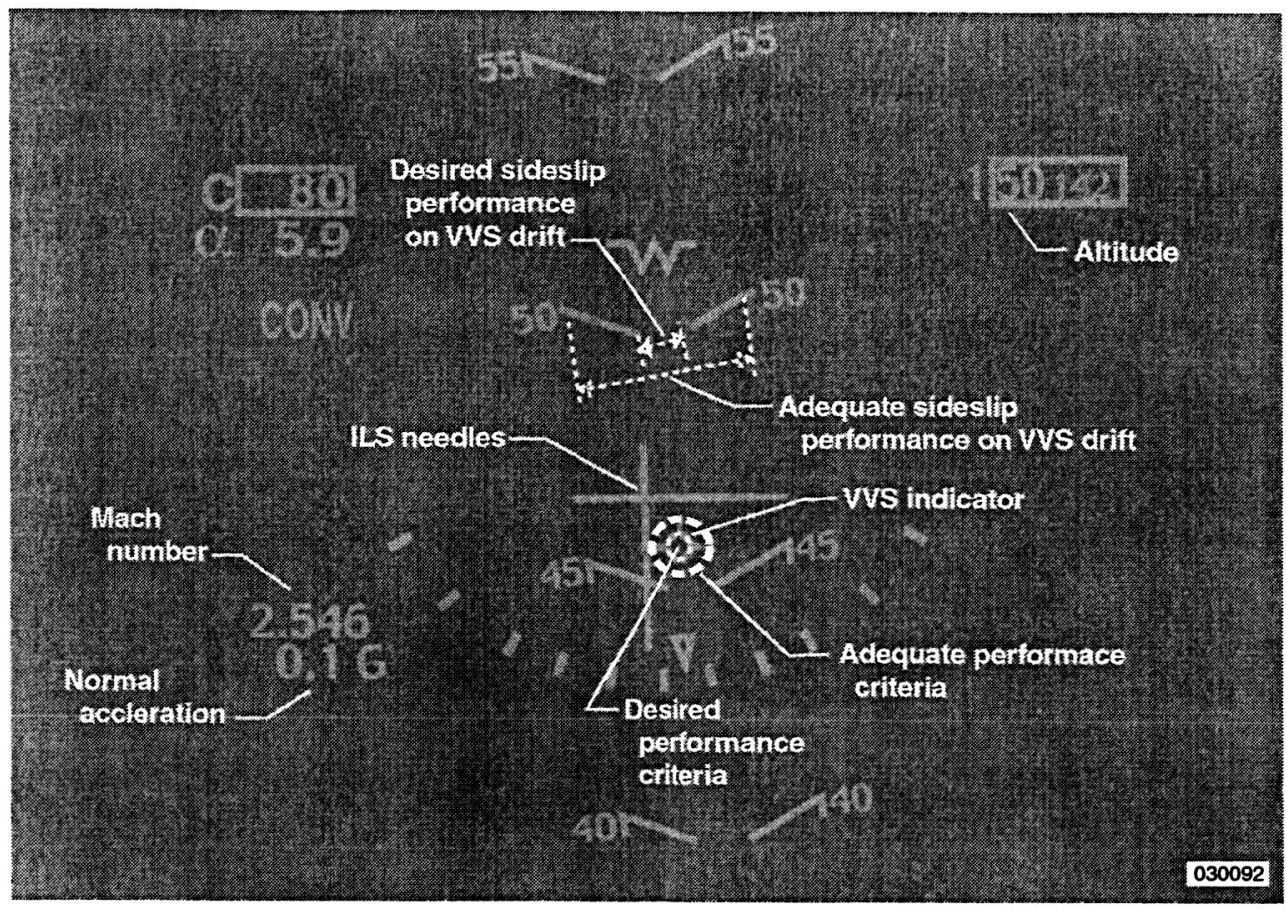

Figure 8. Head-up display (HUD) used in simulation study.

Figure 9 shows how the guidance gains changed during a typical run. The error signals, based on the range traversed, were derived as the difference between the current state and the reference trajectory state. The horizontal needle provided altitude and pitch attitude error commands to the pilot during the level acceleration and the nonballistic portion of the pullup, switched to a pure pitch attitude error command during the initial ballistic portion of the pullup, and switched to an angle-of-attack error command when the desired reentry angle of attack was first achieved. The vertical needle provided crosstrack error and crosstrack rate commands to the pilot during the level acceleration and initial nonballistic part of the pullup, switched to bank-angle error (wings level commanded) when the RLV became ballistic and the pilot no longer was able to command crosstrack error corrections. Transitions in the needles between the various parameters were blended during 5-sec intervals.

Piloting technique required the pilot to null horizontal and vertical needle error deflections by centering both needles on the HUD VVS. For example, if the horizontal needle deflected above the VVS, the pilot had to pull up until the horizontal needle was centered on the VVS. Similarly, if the vertical needle deflected to the right of the VVS, the pilot had to turn right until the vertical needle was centered on the VVS. The VVS had to be in the center of the HUD pitch ladder to maintain a $0^{\circ}$ angle of sideslip $(\beta=0)$ during the ballistic phase, and pilot control of sideslip was accomplished by use of the rudder pedals. The throttles were set at the maximum thrust setting throughout the entire RLV trajectory for all runs.

Trajectories resulting from the use of this guidance scheme compared well to the nominal reference trajectory, indicating that this guidance trajectory definition approach is satisfactory. 

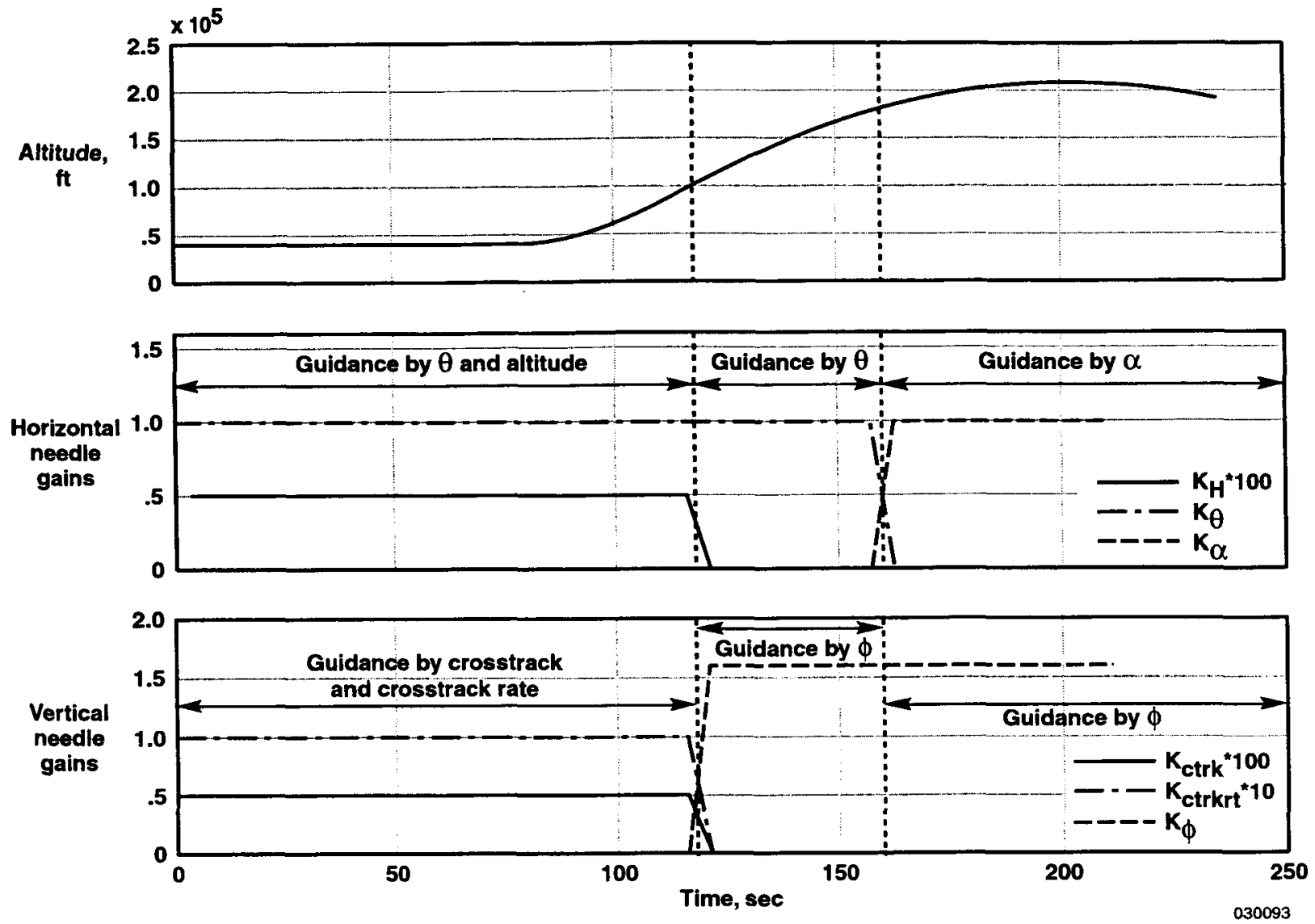

Figure 9. Gain changes in the guidance algorithms for a nominal run.

\section{Wind Profile Variations}

Two wind profiles were defined for use in the simulation study. To document the errors in launch condition in the presence of representative winds, actual rawindsonde balloon data (fig. 10) was incorporated into the simulation. Because aircraft heading was approximately $230^{\circ}$ during the maneuver, the wind profile added significant wind shear inputs during the aircraft pullup. At some point during the climb, winds were expected to be negligible. For this simulation the windspeed was extrapolated to zero over a $4000-\mathrm{ft}$ increment from the last altitude where data were measured.

A second wind profile was generated to provide a tailwind during the maneuver. The windspeed varied from 50 to $60 \mathrm{kts}$ at a direction of $50^{\circ}$ from true north. From an altitude of 54,000 to $60,000 \mathrm{ft}$, the windspeed was interpolated to zero. 

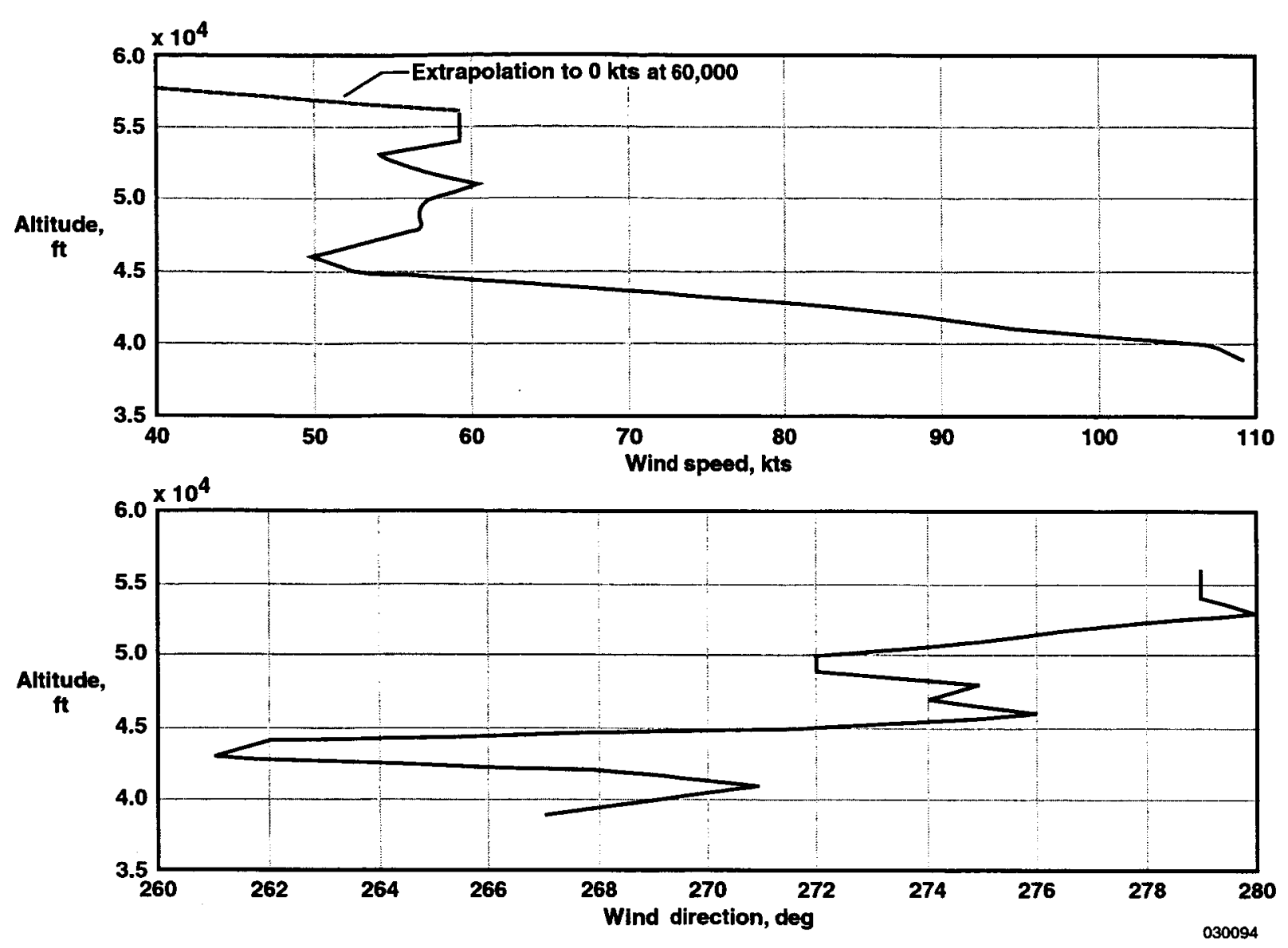

Figure 10. Rawindsonde balloon data.

\section{ELV Transfer Orbit}

The determination of the required ELV launch flight condition is a multivariable problem that depends, in part, on the inclination, $i$; desired longitude of the ascending node, $\Omega$; and altitude of the operational orbit. For this study, the design operational orbit was assumed to be a geocentric, circular, $500-\mathrm{km}$-altitude $(269.97-\mathrm{nmi})$ sun synchronous orbit. The inclination, $i$, of this orbit, therefore, must be ${ }^{9}$

$$
i=\cos ^{-1}\left\{\left[\left(-a^{7 / 2}\right)(2)\left(1.606378006 \times 10^{-4}\right)\left(1-\mathrm{e}^{2}\right)^{2}\right] /\left[(3)\left(R_{\oplus}^{2}\right)\left(\mathrm{J}_{2}\right)\left(\mu_{\oplus}^{1 / 2}\right)\right]\right\}
$$

which yields $i=97.401625^{\circ}$, where the eccentricity $\mathrm{e}=0$, the semimajor axis $a=R_{\oplus}+500 \mathrm{~km}$ $(270 \mathrm{nmi}), R_{\oplus}=6378.1363 \mathrm{~km}(3444.194 \mathrm{nmi}) \equiv$ Earth's equatorial radius, $\mu_{\oplus}=3.986004415 \times 10^{5}$ $\mathrm{km}^{3} / \mathrm{sec}^{2}\left(62765.22 \mathrm{nmi}^{3} / \mathrm{sec}^{2}\right) \equiv$ Earth's gravitational parameter, and $\mathbf{J}_{2}=0.00108263 \equiv$ dimensionless geopotential coefficient. ${ }^{10}$ Equation 3 requires the use of canonical units for $a, R_{\oplus}$, and $\mu_{\oplus}$. That is, $a=\left(R_{\oplus}+500 \mathrm{~km}\right) / R_{\oplus}=1.0783928057 \equiv$ canonical form of $a, R_{\oplus}=1 \equiv$ canonical form of $R_{\oplus}$, and $\mu_{\oplus}=1$ $\equiv$ canonical form of $\mu_{\oplus}$. 
Once $i$ is known, the inertial launch azimuth, $\psi$, can be computed as follows: ${ }^{9}$

$$
\psi=\sin ^{-1}\left\{\cos (i) / \cos \left(\lambda_{\mathrm{gc}}\right)\right\}
$$

(ascending node side of operational orbit)

or

$$
\psi=180^{\circ}-\left(\sin ^{-1}\left\{\cos (i) / \cos \left(\lambda_{\text {gc }}\right)\right\}\right)
$$

(descending node side of operational orbit)

where $\psi$ is an angle measured from true north, and $\lambda_{\mathrm{gc}}$ is the geocentric latitude of the launch location. Only ELV launches on the descending node side of the operational orbit were considered in this study. Further, the auxiliary angle, $\eta$, is given by

$$
\eta=\cos ^{-1}\{\cos (\psi) / \sin (i)\}
$$

(direct orbit)

$$
\eta=360^{\circ}-\cos ^{-1}\{\cos (\psi) / \sin (i)\}
$$

(retrograde orbit)

where $\eta$ (for the retrograde orbit case in this study), with the longitude of the launch point, $\mathrm{l}$, and a choice of the longitude of the ascending node, $\Omega$ (which is driven by mission orbit design requirements), yields the Greenwich sidereal time, $\tau_{\mathrm{GST}}$, of launch

$$
\tau_{\mathrm{GST}}=\Omega+\eta-\mathbf{\imath}
$$

which translates to a time of day for launch, universal time, $U T$, given by

$$
U T=\left(\tau_{\mathrm{GST}}-\tau_{\mathrm{GST} 0}\right) /\left(\omega_{\oplus}\right)
$$

where $\tau_{\mathrm{GST} 0}$ is the Greenwich sidereal time at zero hours on the launch day, and $\omega_{\oplus}$ is the Earth's rotation rate and is equal to $7.292115 \times 10^{-5}+/-1.5 \times 10^{-12} \mathrm{rad} / \mathrm{sec} .{ }^{9}$ The $\tau_{\mathrm{GST}}$ and $\tau_{\mathrm{GST} 0}$ are angles in units of radians.

The reference ELV transfer orbit from the launch point to the operational orbit was derived using the values of the launch flight condition for the RLV as the initial condition for computation of the transfer orbit. Figure 6 and table 2 show these initial values. Table 2 presents the parameters for the launch initial condition with respect to the rotating Earth reference frame (with the exception of $\psi$ ). Computation of the ELV transfer orbit from the RLV separation and launch point to the operational orbit intersection and insertion point requires that all quantities be expressed with respect to the geocentric (nonrotating inertial) reference frame. Specifically, launch separation true airspeed, $V$, and launch flightpath angle, $\gamma$, are corrected to the corresponding geocentric, inertial reference frame launch speed, $V_{\mathrm{i}}$, and launch flightpath angle, $\gamma_{\mathrm{i}}$, by means of the following relationships: 


$$
V_{\mathrm{ix}}^{2}=\left(V^{2}\right)\left(\cos ^{2}(\gamma)\right)+\left(\omega_{\oplus}^{2}\right)\left(R_{\mathrm{lnch}}^{2}\right)\left(\cos ^{2}\left(\lambda_{\mathrm{gc}}\right)\right)-2 V \omega_{\oplus} R_{\mathrm{lnch}} \cos (\gamma) \cos \left(\lambda_{\mathrm{gc}}\right) \cos \left(270^{\circ}-T C\right)
$$

where $R_{\text {Inch }} \equiv$ geocentric radius of RLV at launch, $T C \equiv$ launch azimuth in the rotating Earth reference frame (RLV true course at launch), and $V_{\mathrm{ix}} \equiv$ horizontal component of geocentric, inertial speed. Continuing,

$$
V_{\mathrm{iy}}=V \sin (\gamma)
$$

where $V_{\text {iy }}$ is the vertical component of geocentric, inertial speed. Therefore,

$$
V_{\mathrm{i}}=\left(V_{\mathrm{ix}}^{2}+V_{\mathrm{iy}}^{2}\right)^{1 / 2}
$$

and

$$
\gamma_{\mathrm{i}}=\tan ^{-1}\left(V_{\mathrm{iy}} / V_{\mathrm{ix}}\right)
$$

which applies for a no-wind condition at the launch point in a standard atmosphere. All cases were set up so that the launch point flight condition occurred with zero wind (no winds were inserted into the simulation above $60,000 \mathrm{ft}$ ). The launch separation true airspeed, $V$, is obtained from the relationship $\mathrm{M}=V / V_{\text {sound }}$, where $V_{\text {sound }} \equiv$ the speed of sound at the launch flight condition in a standard atmosphere.

The quantities of launch condition $V_{\mathrm{i}}$ and $\gamma_{\mathrm{i}}$, computed in equations 10 and 11 , respectively, were used with the other launch condition parameters to compute a transfer orbit using standard two-body astrodynamic analysis techniques. A geocentric speed of $V_{\mathrm{T}}=6 \mathrm{~km} / \mathrm{sec}(3.239 \mathrm{nmi} / \mathrm{sec})$, required to be on the transfer orbit at the launch point, was iteratively selected, and the ELV was assumed to have the launch condition values of $V_{\mathrm{i}}, \gamma_{\mathrm{i}}$, and $\psi$ at separation from the RLV. An impulsive (zero time) rocket engine burn was assumed to have occurred at the launch point. The burn provided the $\Delta V_{1}=V_{\mathrm{T}}-V_{\mathrm{i}}$ required to insert the ELV into the transfer orbit at the launch point, with a flightpath angle of $\gamma_{i}$, speed of $V_{\mathrm{T}}$, and launch azimuth of $\psi$. The specific mechanical energy of the ELV transfer orbit, $\varepsilon$, is given by

$$
\varepsilon=\left(V_{\mathrm{T}}^{2} / 2\right)-\left(\mu_{\oplus} / R_{\text {lnch }}\right)
$$

and the specific angular momentum of the ELV transfer orbit, $\chi$, is given by

$$
\chi=\left(R_{\text {lnch }}\right)\left(V_{\mathrm{T}}\right) \cos \left(\gamma_{\mathrm{i}}\right)
$$

which are both constants of the transfer orbit motion. The ELV transfer orbit ends when it first crosses the geocentric radius of the operational orbit, at which time a second rocket engine burn is made to provide the velocity vector change, $\Delta V_{2}$, required to intercept and insert the payload into the operational orbit. Figure 11 shows a diagram of the ELV transfer orbit. 


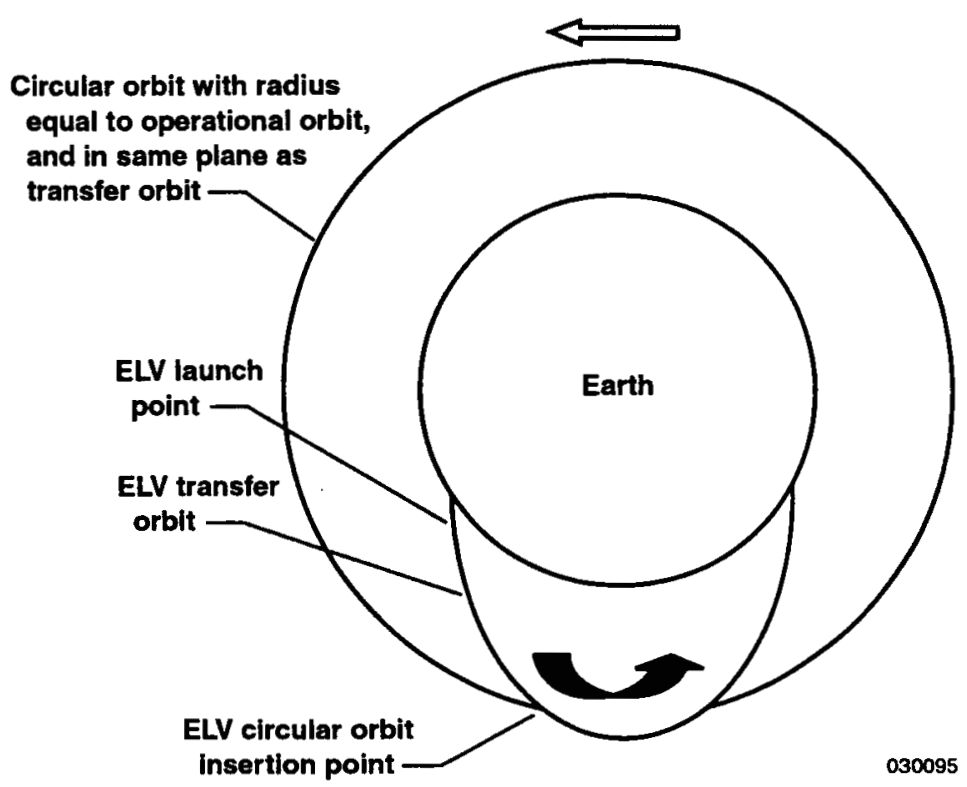

Figure 11. The expendable launch vehicle transfer orbit.

As previously stated, to compute the transfer orbit parameters, standard two-body astrodynamic analysis techniques with impulsive velocity vector changes were used with the forementioned equations. To accomplish the ELV transfer to the operational orbit, the nominal transfer orbit was computed using the forementioned algorithms with the nominal RLV launch flight condition parameters as inputs. Any variations from the nominal values in the RLV launch flight condition parameters propagate through the subsequent ELV transfer orbit, causing errors with respect to the nominal transfer orbit.

\section{TEST METHOD}

Four research pilots flew the following five test cases:

1. Nominal case

2. Initial offset case of 0.5 -mile crosstrack and $500-\mathrm{ft}$ altitude (inserted at the beginning of level acceleration)

3. Tailwind case

4. Actual wind profile case with wind shear

5. Thrust multiplier case of -3 percent to the unaugmented engine (approximating the effect of a nonstandard hot day on a high-performance jet engine)

After several practice runs to become familiar with the zoom maneuver, the research pilots completed two simulation sessions consisting of each of the five cases. The time histories of the runs were recorded to define the launch condition of the ELV. After each data run, the pilots were asked to make comments and provide a rating based on the Cooper-Harper rating (CHR) (fig. 12). ${ }^{11}$ The CHR is an assessment 
tool for evaluating the ease and precision with which a pilot performs a defined task. The scale requires that a desired and adequate level of task performance be defined. The pilot performs the tasks and then works through the decision tree (fig. 12). A CHR is identified based on the level of performance achieved and the degree of difficulty in achieving it. Many of the handling qualities criteria defined in the MIL-STD ${ }^{12}$ specify three levels of handling qualities, which are mapped into the CHRs as shown in figure 12 and table 3 :

CHRs were obtained for the lateral and longitudinal axes for three segments of the zoom maneuver: the level acceleration, nonballistic pullup, and ballistic segments. Desired and adequate performance for the zoom climb task is described in table 4 and shown in figure 8 :

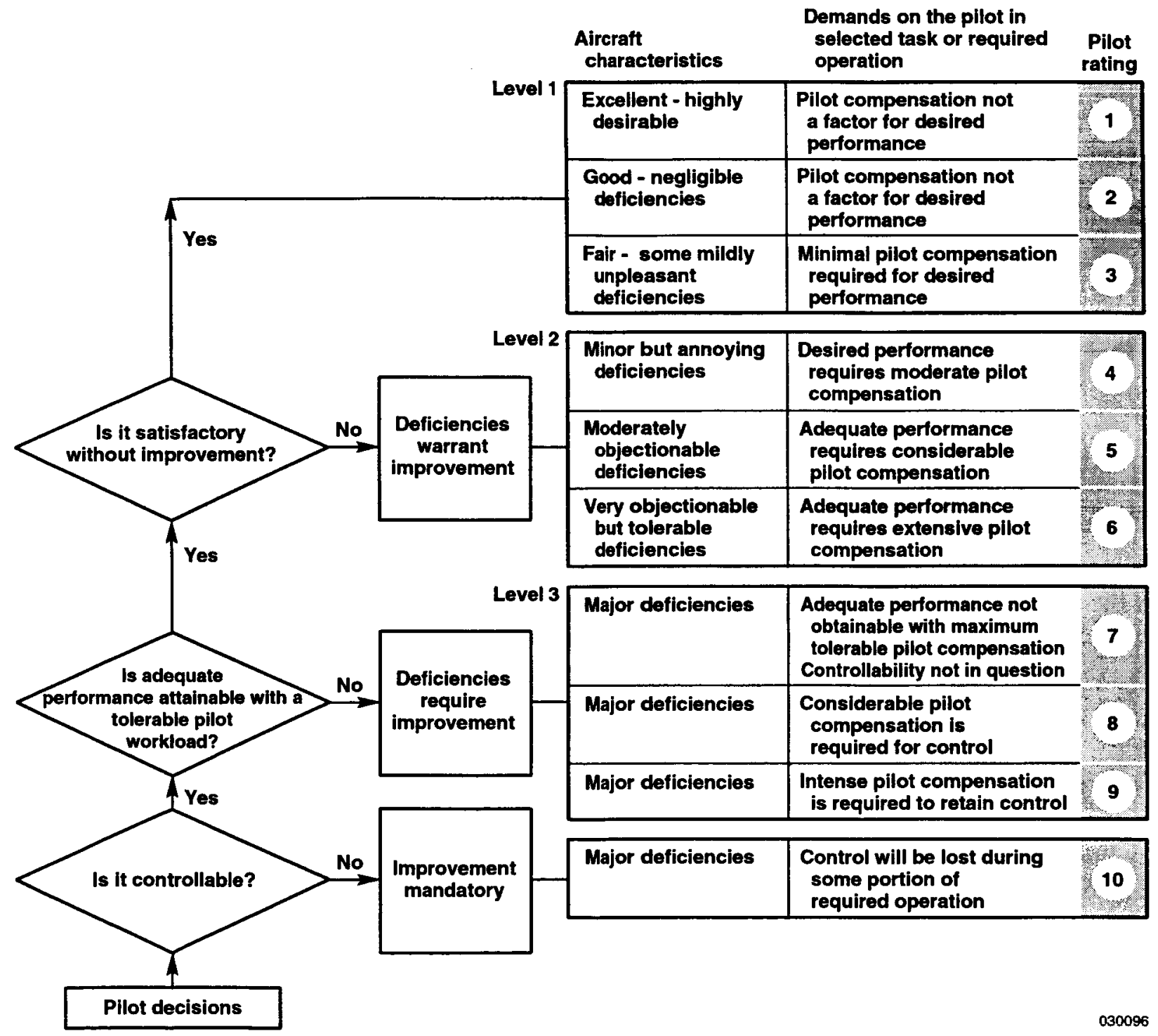

Figure 12. Cooper-Harper rating. 
Table 3. Handling qualities levels compared to Cooper-harper ratings.

\begin{tabular}{cll}
\hline Level & Description & CHR \\
\hline 1 & satisfactory & $1-3$ \\
2 & acceptable & $4-6$ \\
3 & controllable & $7-9$ \\
\hline \hline
\end{tabular}

Table 4. Performance measure for Cooper-Harper ratings.

\begin{tabular}{ll}
\hline \hline Performance Level & \multicolumn{1}{c}{ Criteria } \\
\hline Desired & - $\begin{array}{l}\text { Maintain needles within circle of VVS (dashed } \\
\text { white line) }\end{array}$ \\
- & $\begin{array}{l}\text { Correct VVS to be within gap in the middle of } \\
\text { the pitch ladder during descent to maintain a } 0^{\circ} \\
\text { angle of sideslip ( } \beta \text { ) }\end{array}$ \\
Adequate & Maintain needles within extended tips of VVS \\
& (dashed white line) \\
& Correct VVS to be within outer sides of pitch \\
& $\begin{array}{l}\text { ladder brackets during descent to maintain a } \\
\text { nearly } 0^{\circ} \text { angle of sideslip }\end{array}$ \\
\hline \hline
\end{tabular}

Specific comments were requested concerning the simulation setup, HUD, and ease and precision with which the needles could be tracked. In addition, the pilots were asked to identify the most difficult part of the maneuver.

The corresponding ELV launch flight condition for each run was then inserted into the ELV transfer orbit algorithm to determine the resulting ELV transfer orbit. The ELV launch condition errors in $H, V$, $M, \psi$, and $\gamma$ occurring between each run and the reference RLV trajectory were calculated. The ELV launch flight condition errors were propagated through the ELV transfer orbit computations to determine ELV transfer orbit errors.

\section{RESULTS}

This section discusses the simulation test results. The ELV launch condition error and handling qualities in the zoom maneuver, and ELV transfer orbit effects are described in detail. 


\section{ELV Launch Condition Error and Handling Qualities in the Zoom Maneuver}

Figure 13 compares the reference trajectory to a nominal trajectory run. The crosstrack for the baseline case is zero by definition. The pilot generally flew the reference trajectory very well for all the cases except the engine thrust variation case. Figure 14 compares the launch conditions for the pilot-in-the-loop simulation runs to the launch conditions for the reference trajectory. The figure shows that the engine thrust case resulted in significantly more error in launch condition for all parameters. The wind shear case resulted in significant variation in the launch inertial azimuth. Furthermore, the wind shear case apparently provided more deviation from the reference trajectory in altitude and Mach number than did the nominal, tailwind, and offset cases. No correlation in deviations was noted with respect to pilot performance. Table 5 approximates the launch condition deviations for the thrust multiplier case, and the nominal, wind shear, tailwind, and offset cases (combined).

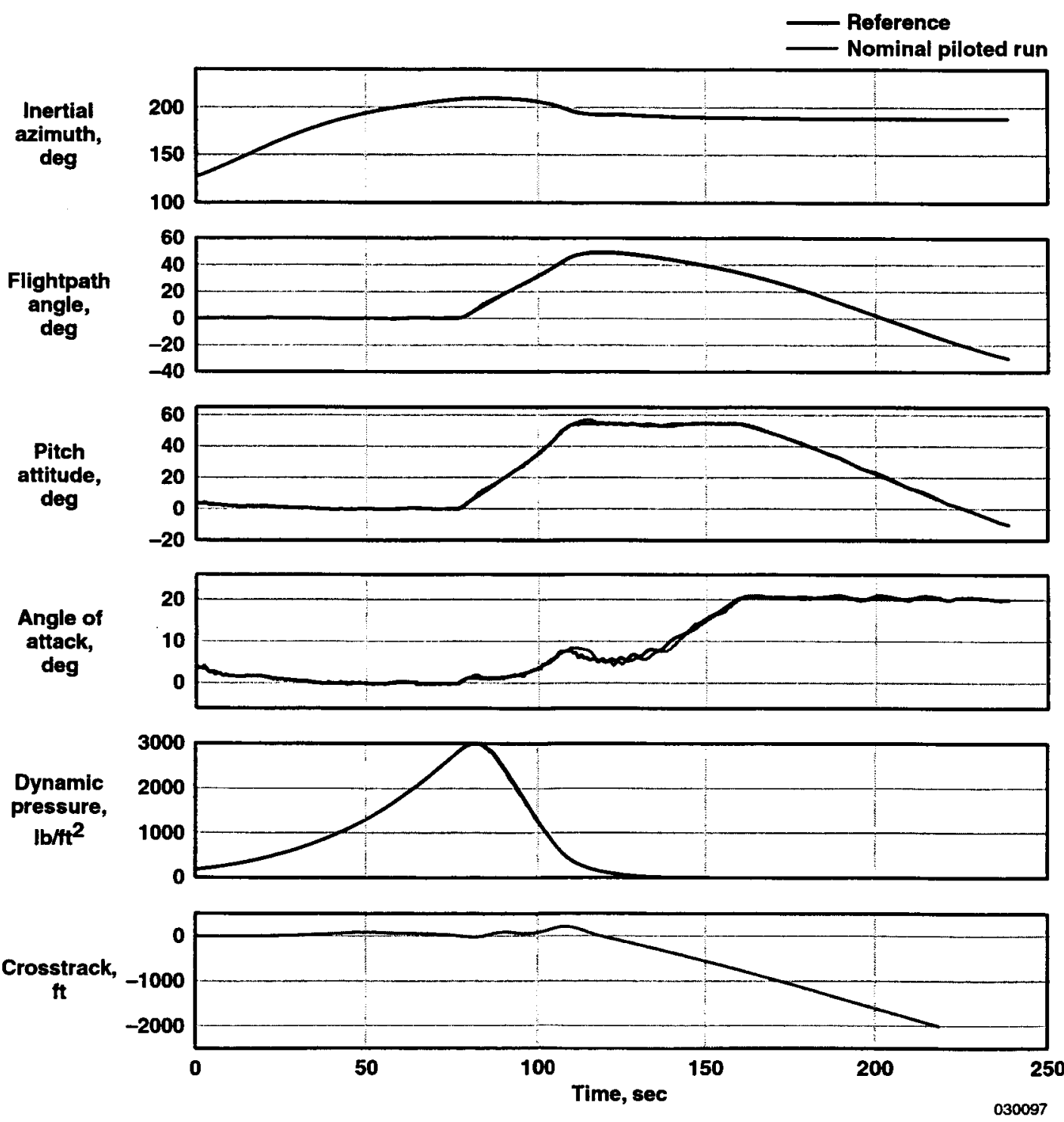

Figure 13. Comparison of reference trajectory to the nominal trajectory. 
Table 5. Approximate deviation in launch condition.

\begin{tabular}{lcc}
\hline \hline Parameter & Thrust Multiplier Case & Other Cases Combined \\
\hline Altitude & $-6,000 \mathrm{ft}$ & $-1,150 \mathrm{ft}$ \\
Time & $-16 \mathrm{sec}$ & +3 to $-4 \mathrm{sec}$ \\
Mach number & -0.25 & -0.05 \\
Flightpath & $-15.0^{\circ}$ & $+1.8^{\circ}$ \\
Azimuth & $-4.5^{\circ}$ & $+0.25^{\circ}$ to $-1.5^{\circ}$ \\
\hline \hline
\end{tabular}
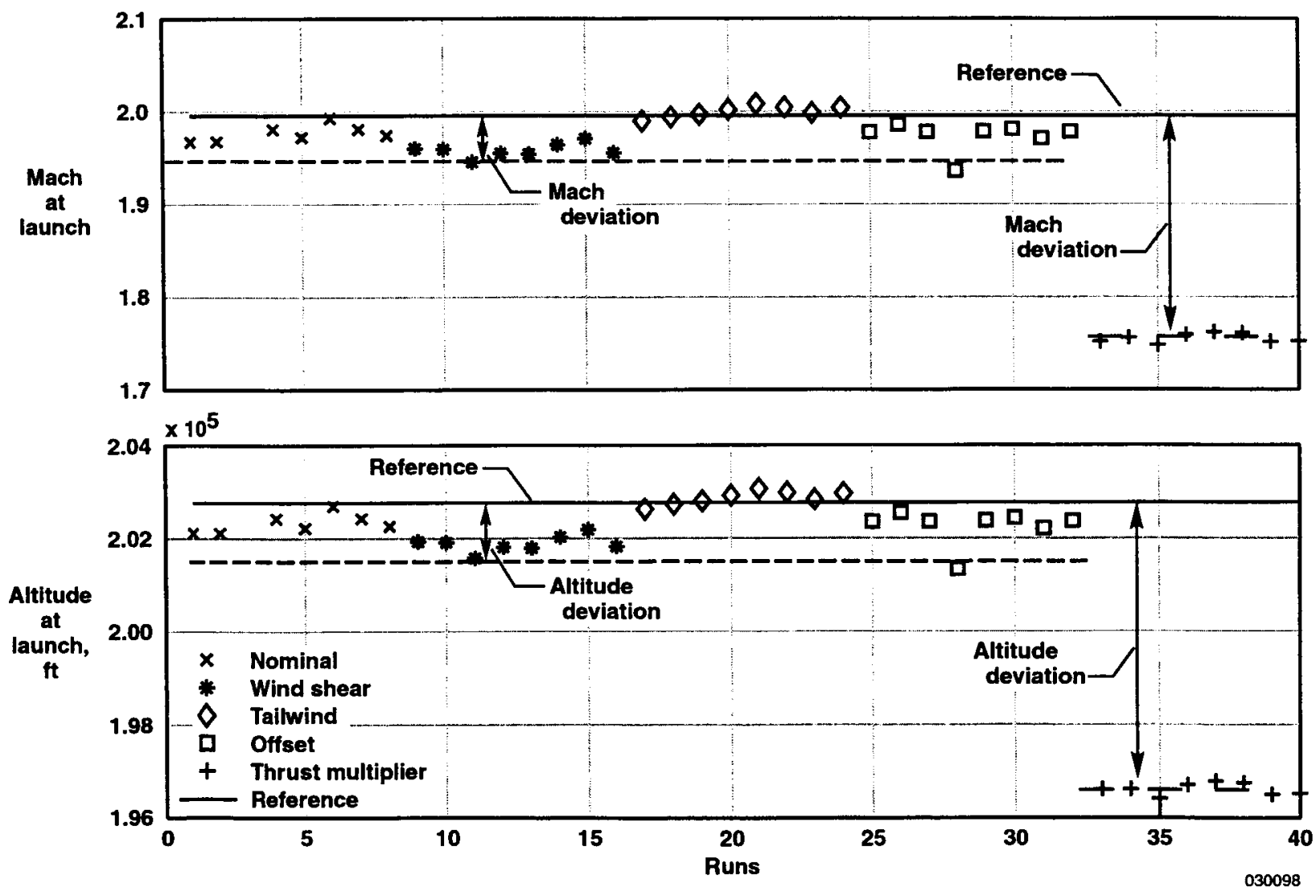

(a) Altitude and Mach deviation.

Figure 14. Expendable launch vehicle launch conditions compared to reference trajectory launch conditions. 

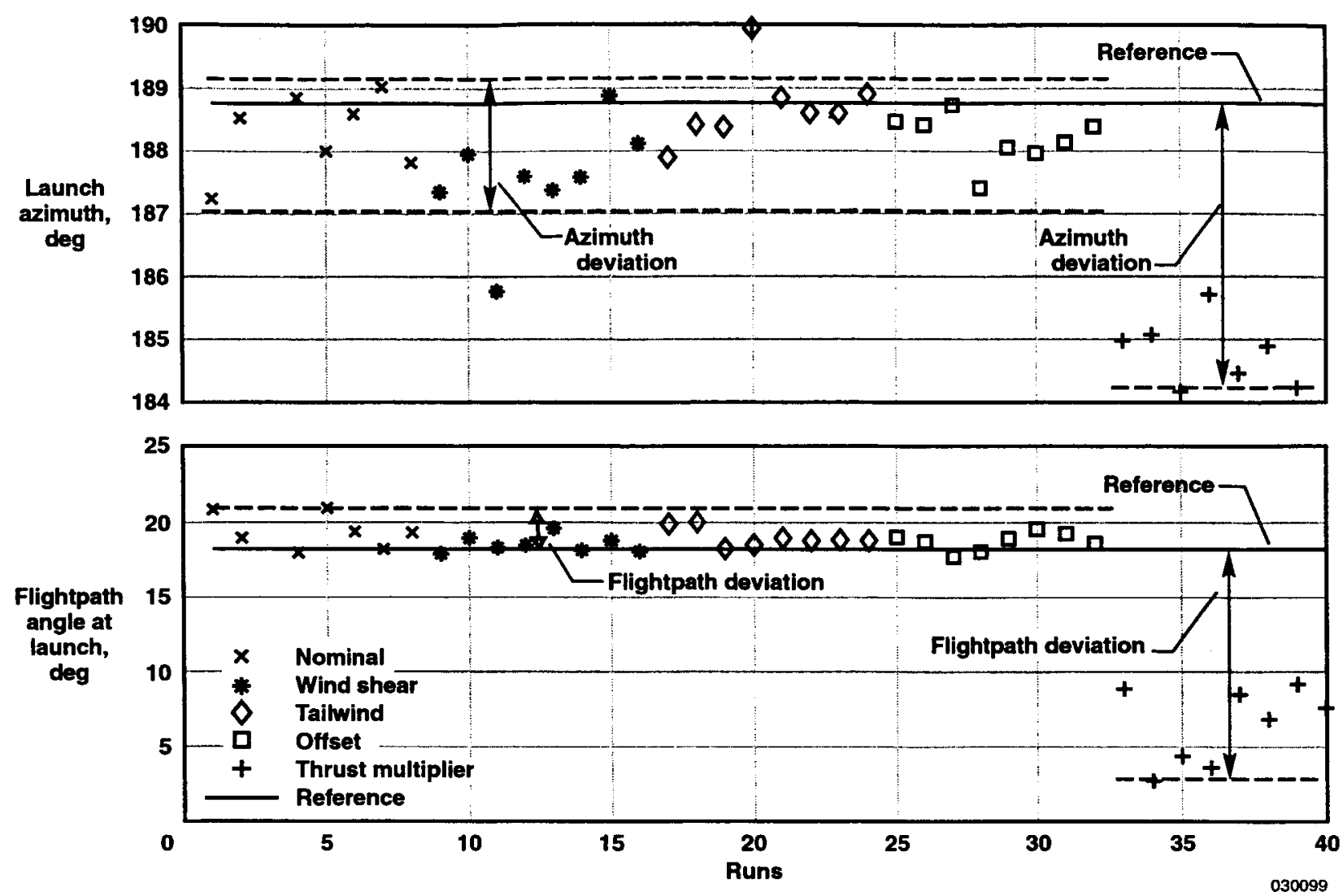

(b) Flightpath and azimuth deviation.

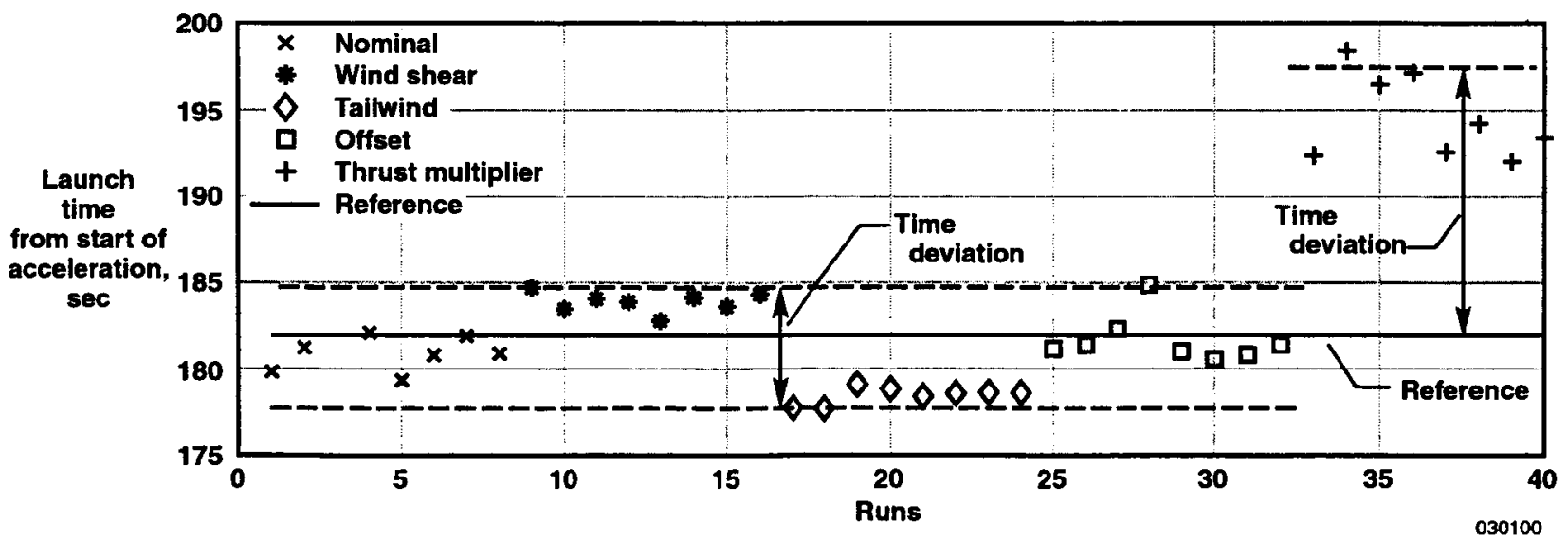

(c) Time deviation.

Figure 14. Concluded. 
For comparison, deviations in the X-15 program were documented in reference 5 as 2 percent in altitude, corresponding to approximately $4000 \mathrm{ft}$ for the profile in this study, and $2^{\circ}-3^{\circ}$ in heading.

Figure 15 shows the CHRs for each of the three portions of the maneuver. The level acceleration was considered to be level 1 by all the pilots. The pilots generally considered the roll axis as level 1 , with the exception of pilot 3 in the pullup and ballistic phases.

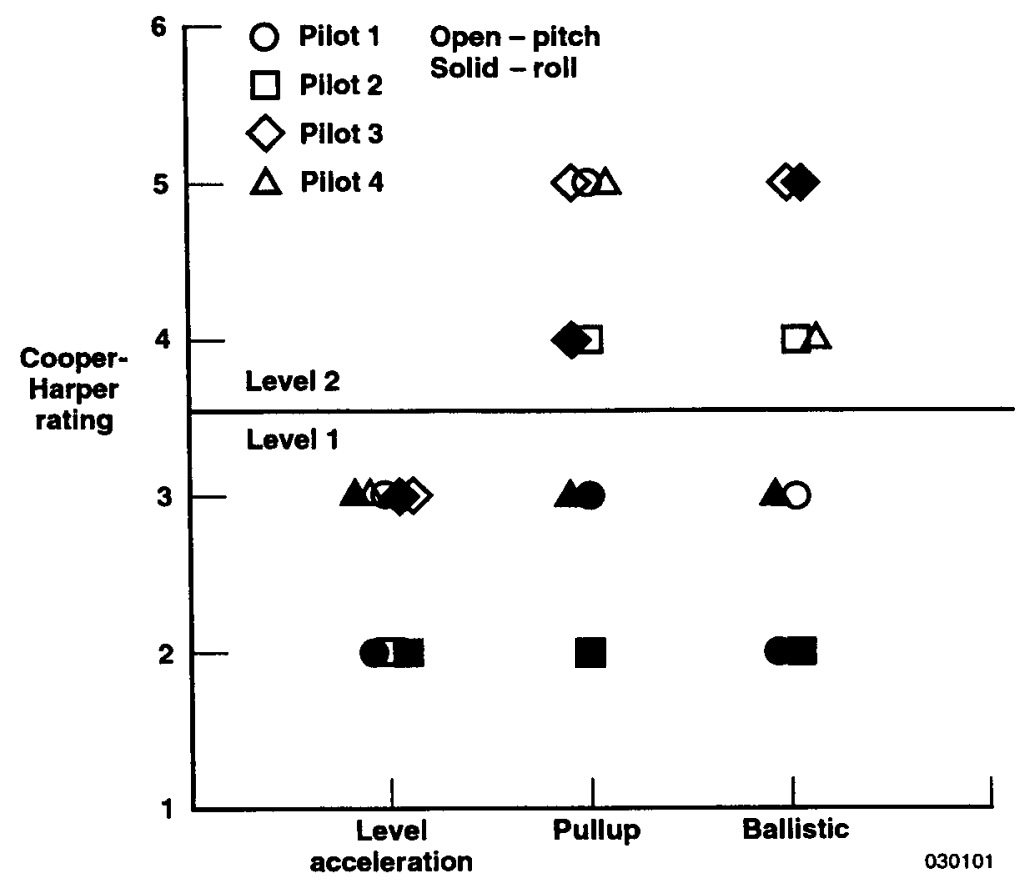

Figure 15. Pitch and roll Cooper-Harper ratings for each phase of flight.

\section{Pullup Phase Evaluation}

From a handling qualities perspective, all the pilots felt that the nonballistic pullup was unsatisfactory without improvement. The level 2 ratings for the longitudinal axis primarily were based on an inability to predict the stick force necessary for desired aircraft response during constantly changing conditions. Comments from pilots 1 and 2 indicated that the heavy stick forces required in the pull were undesirable and contributed to the lack of predictability. Pilot 3 did not indicate that stick forces were too heavy but felt that the stick deflection necessary to make corrections for large errors was nonlinear and nonintuitive. A stair-stepping characteristic in the horizontal needle and insufficient anticipatory cues, especially at the pullup condition and the pushover to capture the climb attitude, also contributed to the pilot's rating. Comments from pilot 4 were similar to those from pilot 3, noting high workload for this portion of the maneuver.

The stair-stepping characteristic of the horizontal needle is related to the altitude error command derivation driving the horizontal needle. The error was calculated using a digitized match of the reference altitude. The break points for the reference altitude table implemented in the simulation ranged from 
3 to $7 \mathrm{sec}$ apart with linear interpolation for data in between. Although the typical error between the digitized altitude command and the reference altitude was $200 \mathrm{ft}$ or less, the altitude variation between break points during the climb portion had enough curvature to cause abrupt error commands in the horizontal needle. Figure 16 shows time histories of the altitude error and horizontal needle error for an offset case flown by pilot 2 . At the beginning of the pullup phase, the abrupt, hump-like characteristic is observed in the altitude error trace. This error is passed to the horizontal needle error, which is displayed to the pilot. The amplitude of each jump varies, but consistently ranges between desired and adequate performance. All the pilots noticed this characteristic, and it appears to have contributed to their comments on unpredictable pitch response. Once ballistic, the gain on the altitude error transitions to zero, and the hump-like characteristic disappears from the horizontal needle error. An enlarged portion of the time history (fig. 17) distinctly shows how the difference between the discrete altitude command and the altitude causes the spike-like characteristic in the error signal.

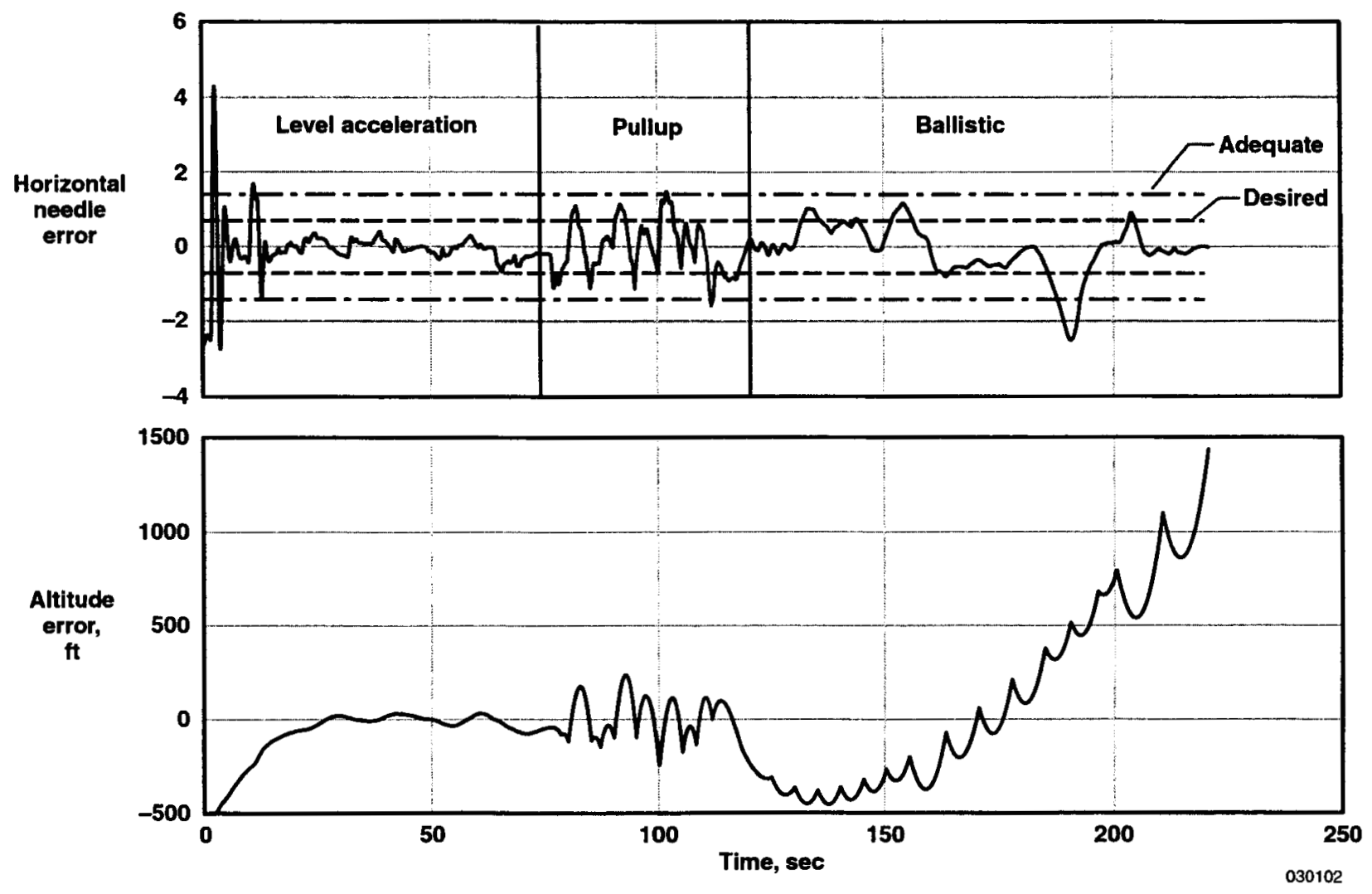

Figure 16. Time histories of the altitude error and horizontal needle error. 


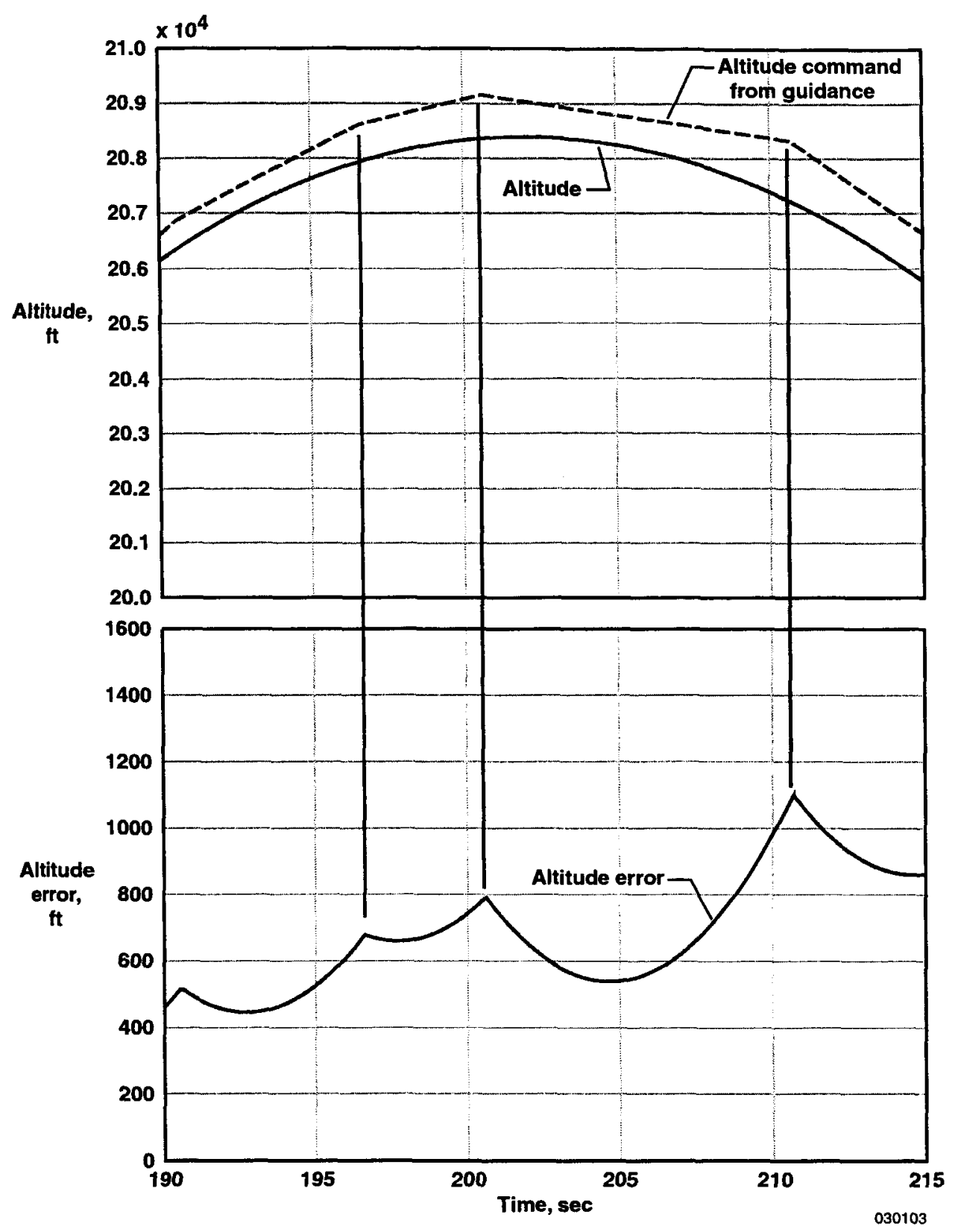

Figure 17. Effect of digitized reference altitude on the altitude error displayed to pilot.

Control anticipation parameter (CAP), short period damping, dutch roll damping, and the roll mode time constant were estimated during the level acceleration and nonballistic pullup and were compared to handling qualities criteria defined in reference 12. The estimates were rated level 1, except for the short period damping immediately before the pullup, which was rated level 2 . Although pilots commented on a bobbling tendency in the pitch axis, they rated this portion of the flight as level 1 . Although the short period damping values were rated level 1 during the pullup, a rapid increase in damping occurred with time, possibly caused by an overly rapid ramp up in the pitch rate feedback gain, which also might have contributed to the unpredictable pitch response noted by the pilots. The damping increase could be countered through less aggressive pitch rate feedback compensation of the bare airframe damping derivative. 


\section{Ballistic Phase Evaluation}

All of the pilots except for pilot 1 rated the pitch axis of the ballistic portion of the maneuver as level 2. The pilots complained about the high workload required to maintain the needles in the center of the flightpath marker, in addition to maintaining the drift of the flightpath marker within the pitch ladder constraint. The workload might be a function of tight constraints on bank angle, sideslip, pitch attitude, and angle of attack, which drive the needles and the flightpath marker drift. Figure 18 shows these parameters during the ballistic portion of a typical nominal run, with desired criteria overlaid.
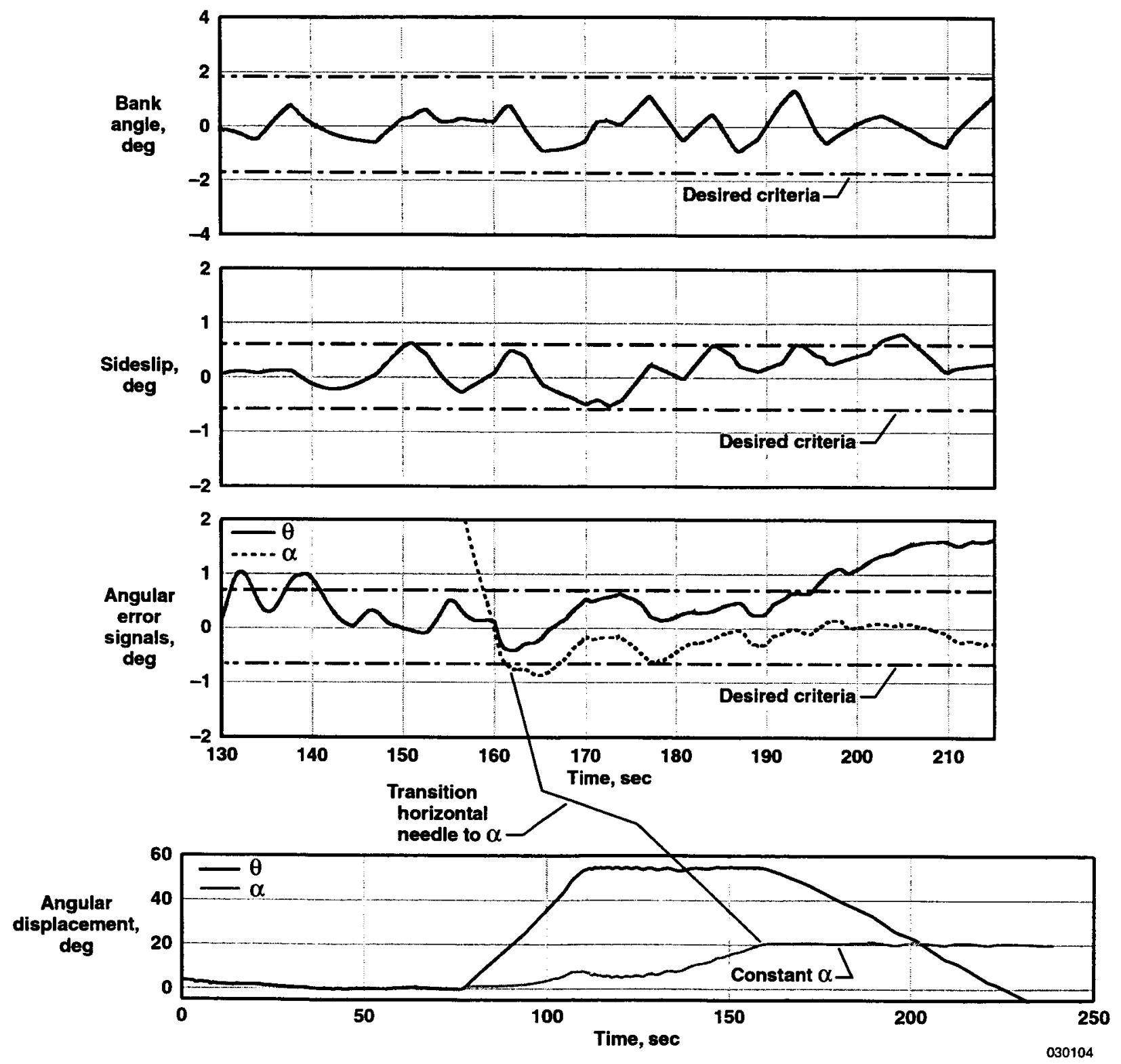

Figure 18. Pilot performance in ballistic phase compared to desired performance criteria. 
The constraints show that desired criteria translate to be less than a $2^{\circ}$ bank-angle deviation, $0.7^{\circ}$ pitch-attitude and angle-of-attack deviations, and a $0.6^{\circ}$ sideslip deviation. The performance levels were met but required a lot of concentration. Although tight constraints on these parameters probably are necessary until after the launch occurs, whether or not the constraints in this study are too restrictive is unclear. After the ELV launch occurs, some of these constraints might be relaxed. Pilots 2 and 4 noted some lag in the horizontal needle, although this factor did not significantly influence the ratings. Pilot 3 indicated that the stick input required to correct large errors in the needles was not intuitively obvious.

\section{Most Difficult Phase}

The pilots disagreed on the most difficult phase of the maneuver. The majority of the pilots identified the pullup portion as the most difficult, whereas pilot 2 felt that it was the ballistic portion. No adverse characteristics were noted for the transitions in the needles generated within the guidance algorithm.

\section{Display Comments}

All the pilots commented on issues related to the display. Most felt that the display for controlling sideslip on the ballistic portion was inadequate. They felt corrections to maintain performance levels were nonintuitive and required more concentration than was desired. In addition, pilots 1 and 4 mentioned that a launch condition predictor from the current state would be advantageous in determining if the current error state was acceptable. Pilots 2 and 4 felt that a pitch pullup cue would help avoid lags on the pullup and reduce the compensation required during the nonballistic climb. Pilot 3 , in addition to expressing the same opinions as those of pilots 1 and 2 , favored a flight director type of display as opposed to the ILS-type needles.

\section{ELV Transfer Orbit Effects}

Variations of several parameters from the reference transfer orbit, including apogee radius, specific mechanical energy, specific angular momentum, total speed change required to insert the ELV onto operational orbit $\left(\Delta V_{\text {tot }}\right)$, eccentricity, inclination, intercept true anomaly, intercept flightpath angle, and universal time at ELV launch, were computed for all the simulation runs. The $\Delta V_{\text {tot }}$ is the sum of the change in geocentric speed required to put the ELV onto the transfer orbit, $\Delta V_{1}$, from the launch flight condition, and the change in geocentric speed required to insert the ELV into a circular $269.97 \mathrm{nmi}$ altitude orbit from the transfer orbit, $\Delta V_{2}$. The $\Delta V_{\text {tot }}$ sum is for insertion of the ELV into a circular orbit with the same radius as the intended operational orbit, but it does not account for any plane change maneuvers that might be required because of inclination, $i$, errors in the transfer orbit. That is, $\Delta V_{\text {tot }}$ accounts for only geocentric speed changes made in the plane of the transfer orbit, with the resultant circular orbit in the same orbital plane as the transfer orbit. Figure 19 shows the ELV transfer orbit data, which is correlated to launch condition parameters. For all test cases except the thrust multiplier case, the ELV was able to achieve the operational orbit radius. 
Figure 19(a) shows the apogee radius of the transfer orbit versus the inertial launch flightpath angle, $\gamma_{i}$. Figure 19(c) shows the inertial flightpath angle at the radius of the operational orbit, or intercept flightpath angle, versus the inertial launch flightpath angle, $\gamma_{\mathrm{i}}$. The apogee radius data generally indicate a linear relationship with inertial launch flightpath angle; the thrust cases have the lowest values of inertial launch flightpath angle, and the nominal cases have the highest values. For the thrust cases, the apogee radius is less than the intended operational orbit radius. Thus no intercept flightpath angle exists, which indicates the RLV energy state at launch was significantly reduced, and the ELV did not achieve the operational orbit radius. The intercept flightpath angle data also exhibit a linear relationship with inertial launch flightpath angle. The linear correlation of both the intercept flightpath angle and apogee radius to $\gamma_{\mathrm{i}}$ implies that minimizing errors in $\gamma_{\mathrm{i}}$ will lead to reduced deviations from the reference transfer orbit, thereby reducing ELV propellant requirements.
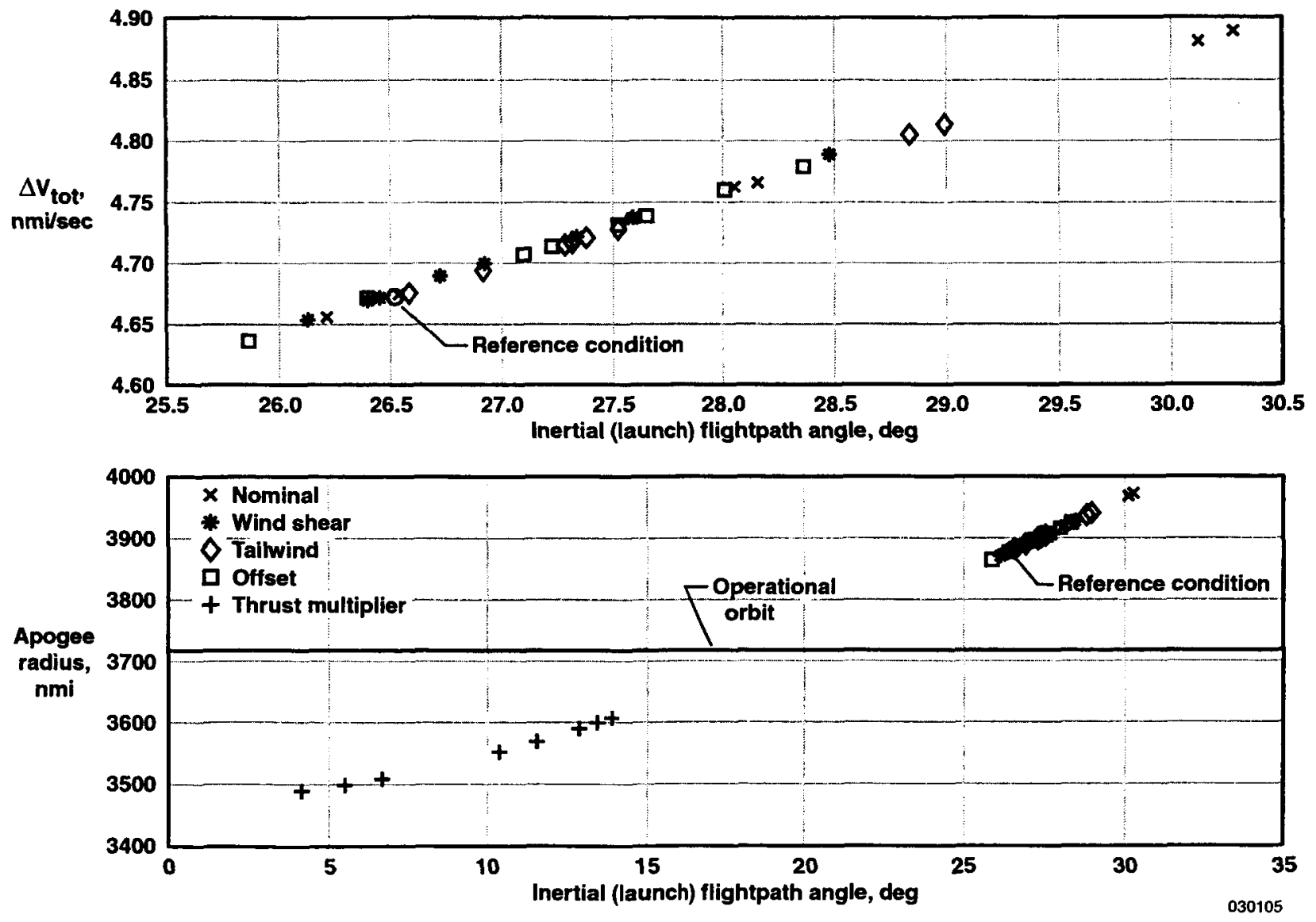

(a) Variation of $\Delta V_{\text {tot }}$ and apogee radius with launch flightpath angle.

Figure 19. Expendable launch vehicle transfer orbit conditions compared to reference condition. 

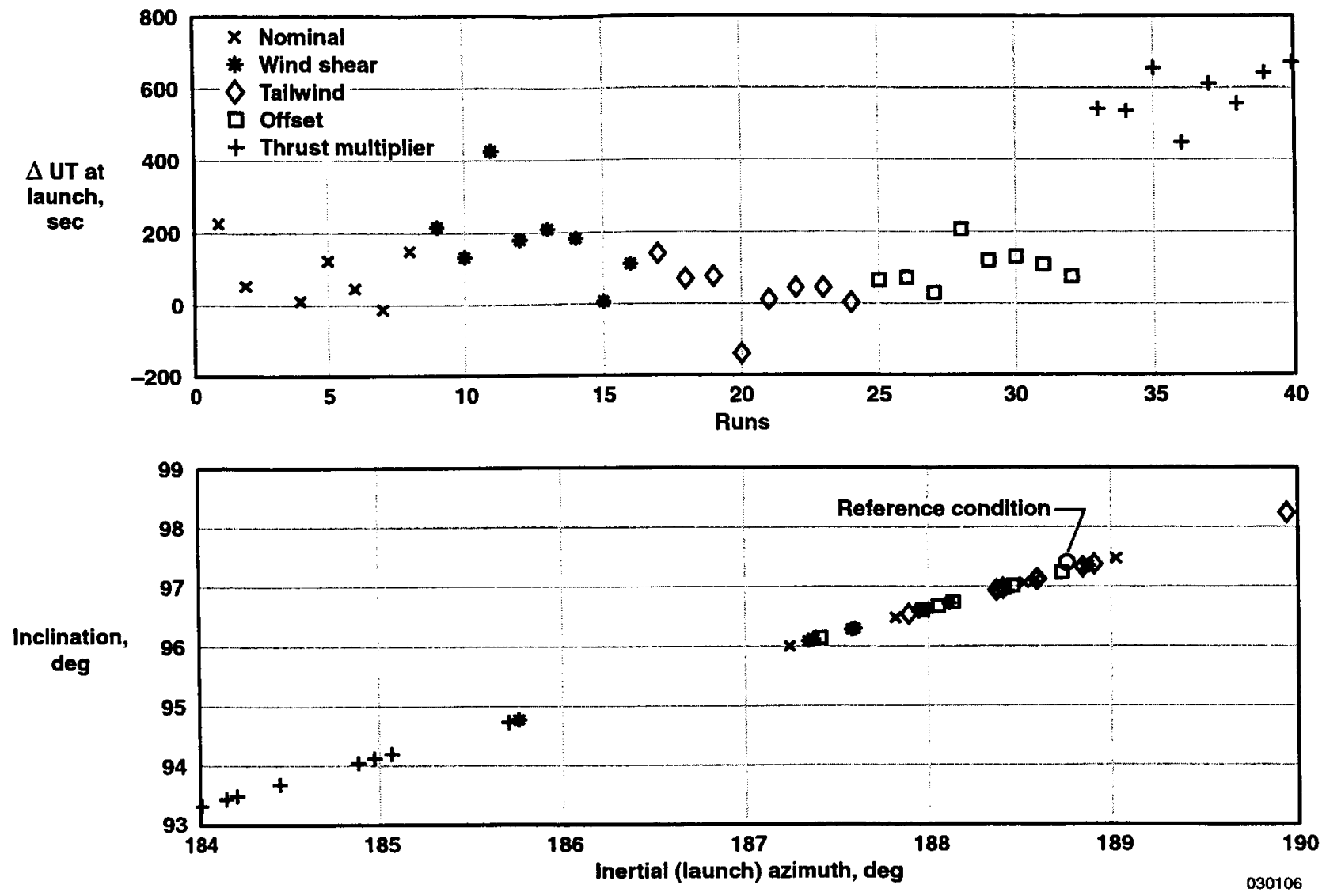

(b) Inclination and $\Delta$ universal time at launch deviation.

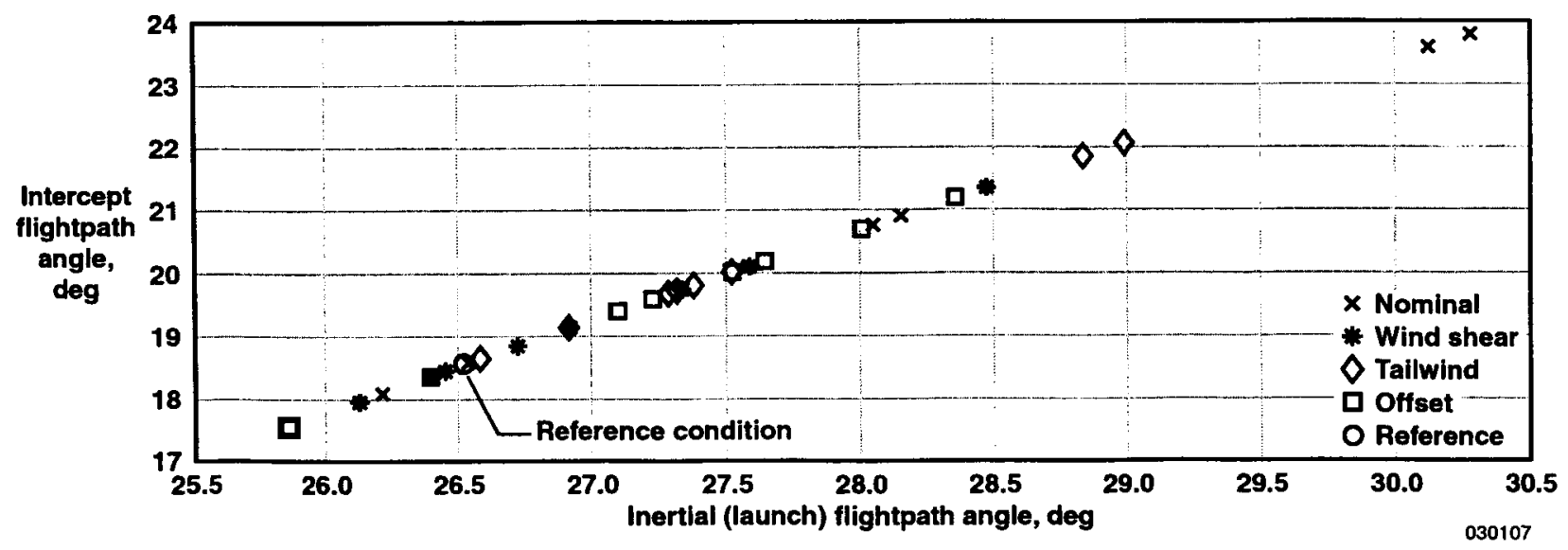

(c) Intercept flightpath angle versus launch flightpath angle.

Figure 19. Concluded. 
The $\Delta V_{\text {tot }}$ required for the ELV transfer orbit versus launch inertial flightpath angle (fig. 19(a)) shows that more $\Delta V_{\text {tot }}$ was required for most of the runs than was required for the reference trajectory. These trends indicate that in most cases energy deficits were greater than those of the reference trajectory case because of variations in the wind vector field, initial offset error at the start of the level acceleration, and piloting technique for reference trajectory tracking. A few of the runs resulted in less $\Delta V_{\text {tot }}$ than that of the reference condition, however, which implies that a more optimal trajectory is possible. Also, the required $\Delta V_{\text {tot }}$ apparently is proportional to the launch flightpath angle. Because propellant requirements are proportional to total $\Delta V_{\text {tot }}$, this correlation corroborates the observations of data in the previous paragraph. Minimizing ELV launch errors in $\gamma_{i}$ is important in reducing the amount of propellant required, which impacts ELV sizing requirements.

The importance of controlling inertial launch azimuth is observed in the following results of a plane change maneuver example, and from examination of figure 19(b). This figure shows that the dispersion in launch azimuth causes the transfer orbit inclination, $i$, to vary between approximately $+93.3^{\circ}$ and $+98.2^{\circ}$. This variation of inclination, compared to the operational orbit inclination $\left(i=97.401625^{\circ}\right)$, would require the ELV to perform an orbit plane change maneuver to achieve the inclination, $i$, required for the operational orbit. This orbit plane change maneuver would require an additional speed change increment, $\Delta V_{\mathrm{pc}}$, in addition to the $\Delta V_{\text {tot }}$ given for each corresponding case (fig. 19(a)), necessitating additional propellant, thereby increasing ELV mass and/or reducing the mass available for the payload.

As an example of the geocentric speed change capability required to change the transfer orbit inclination to the intended operational orbit inclination, the data value of $\Delta i=1.4^{\circ}$ was selected from table 6. In the following analysis, the plane change maneuver is assumed to be initiated from the circular orbit with the radius of the intended operational orbit and inclination equal to the inclination of the transfer orbit. As such, the magnitude of the geocentric speed change required to complete the plane change maneuver, $\Delta V_{\mathrm{pc}}$, is given by ${ }^{9}$

$$
\Delta V_{\mathrm{pc}}=2 V_{\mathrm{op}} \cos \left(\gamma_{\mathrm{op}}\right) \sin (\Delta i / 2)
$$

where $\Delta V_{\mathrm{pc}}=0.186 \mathrm{~km} / \mathrm{sec}(.1 \mathrm{nmi} / \mathrm{sec}), \gamma_{\mathrm{op}}=0 \equiv$ flightpath angle on the circular orbit, and $V_{\mathrm{op}}=7.6126 \mathrm{~km} / \mathrm{sec}(4.11 \mathrm{nmi} / \mathrm{sec}) \equiv$ the geocentric speed required to be on the circular operational orbit and is given by ${ }^{9}$

$$
V_{\mathrm{op}}=\left(\mu_{\oplus} / R_{\mathrm{op}}\right)^{1 / 2}
$$

where $R_{\mathrm{op}}=R_{\oplus}+500 \mathrm{~km} \equiv$ geocentric radius of the operational circular orbit. The magnitude of the speed change required to change the orbital plane is comparable to the deviation of $\Delta V_{\text {tot }}$ from the reference condition. 
Figure 19(b) shows the $\Delta U T$ at launch (that is, the difference between $U T$ at launch for the reference trajectory and a given run) versus each run number. The data in this figure show that the $\Delta U T$ at launch is greater than zero for most cases, and the degraded thrust cases have the largest positive values of time deviation. These results indicate that time guidance to the pilot is necessary and must be added to the reference trajectory pilot guidance system to minimize these launch time errors. Errors in the $U T$ at launch result in errors in the longitude of the ascending node, $\Omega$, of the intended operational orbit. To illustrate the importance of achieving the correct $\Omega$, consider that $\Omega$ is one parameter controlling the orientation of the design operational orbit used in this study such that the payload overflies specific points on the surface of the Earth at essentially the same times of day (thus the same sun angles and lighting conditions at these points on the surface of the Earth). Significant variations in $\Omega$, therefore, can cause mission failure if not correctable through orbital maneuvering, which requires additional propellant mass. Figure 19(b) was generated with $\Omega=45^{\circ}$, which was an arbitrary choice.

Table 6 lists the approximate transfer orbit parameter deviations from the reference values for each of the five test cases. A dash indicates that no value could be found because of a failure to reach the operational orbit radius. The first runs for pilots 1 and 3 have been excluded from the list of transfer orbit deviations because of the learning curve effects seen in these runs.

Table 6. Deviations from reference transfer orbit.

\begin{tabular}{|c|c|c|c|c|c|c|}
\hline Parameter & $\begin{array}{c}\text { Reference } \\
\text { Value }\end{array}$ & \begin{tabular}{|c|} 
Thrust \\
Multiplier
\end{tabular} & Nominal & Wind Shear & Tailwind & Offset \\
\hline Apogee Radius, nmi & 3,880 & -372 & -3 to 35 & -19 to 51 & -3 to 62 & -19 to 46 \\
\hline $\begin{array}{l}\text { Specific Angular } \\
\text { Momentum, } \mathrm{nmi}^{2} / \mathrm{sec}\end{array}$ & 10,081 & 1,166 & -152 to 14.6 & -181 to 14.6 & -233 & -160 \\
\hline $\begin{array}{l}\text { Specific Mechanical Energy, } \\
\mathrm{nmi}^{2} / \mathrm{sec}^{2}\end{array}$ & -0.0128 & -0.00525 & -0.000437 & -0.000875 & $\begin{array}{c}-0.000146 \text { to } \\
0.00029\end{array}$ & $\begin{array}{l}-0.00029 \text { to } \\
-0.000146\end{array}$ \\
\hline $\begin{array}{l}\text { Intercept Flightpath Angle, } \\
\text { deg }\end{array}$ & 18.6 & - & -0.6 to 1.9 & -0.3 to 2.4 & 3.9 & -1.1 to 2.4 \\
\hline Total delta V, nmi/sec & 4.67 & - & -0.016 to 0.092 & $\begin{array}{c}-0.022 \text { to } \\
0.119\end{array}$ & 0.135 & 0.108 \\
\hline Delta True Anomaly, deg & 8.95 & - & -0.75 to 0.15 & -0.95 to 0.25 & -1.15 & -0.95 to 0.1 \\
\hline Orbital Eccentricity & 0.58 & -0.155 & 0.02 & 0.025 & 0.03 & $\begin{array}{c}-0.005 \text { to } \\
0.025 \\
\end{array}$ \\
\hline Inclination, deg & 97.4 & -3.9 & -1.4 to 0.1 & -1.4 & -0.9 to 0.8 & -1.2 \\
\hline Time of Flight, sec & 201 & - & -15 to 4 & -17 to 5 & -21 & -17 to 1 \\
\hline Intercept True Anomaly, deg & 165.45 & - & -1 to 0.25 & -1.3 to 0.4 & -1.6 & -1.2 to 0.1 \\
\hline $\begin{array}{l}\text { Delta Universal Time at } \\
\text { Launch, sec }\end{array}$ & - & 680 & 220 & 210 & 160 & 203 \\
\hline
\end{tabular}




\section{FUTURE RESEARCH}

Improving the handling qualities during the zoom maneuver potentially could improve pilot performance. Based on the results of this study, the following improvements are suggested:

1. Implement display modifications on pullup, pushover, and launch cues.

2. Implement less aggressive rate feedback gain increases during the climb portion.

3. Smooth the digitized altitude used in the guidance algorithm by either decreasing the time interval between break points during the climb and ballistic portions, or using a curved fit instead of a linear fit between break points.

Some additional research not covered in this study would be beneficial to the RASCAL concept. Development of a simple autopilot to perform the trajectory (described in this study) could be used to compare the ELV launch condition deviation with the pilot-in-the-loop deviation. As previously stated, the RASCAL proposal calls for the ELV to deliver a payload to a sun synchronous orbit, which results in an RLV time constraint. The investigation of guidance concepts, which result in the ELV launch at a given time, as well as a position and azimuth in space, would be beneficial. Results from this study imply that atmospheric temperature variations and their influence on thrust must be accounted for within the guidance algorithm. The investigation of guidance algorithms, which make real-time adjustments during the level acceleration and climb to minimize launch condition errors based on reduced thrust levels, would also be of interest. Use of trajectory optimization algorithms would be beneficial to the development of these guidance concepts.

\section{CONCLUSIONS}

An existing Mach-2.5, fighter-type simulation at the NASA Dryden Flight Research Center was modified to simulate a reusable launch vehicle (RLV) in support of the Responsive Access, Small Cargo, and Affordable Launch (RASCAL) program. This simulation was used to quickly evaluate exo-atmospheric zoom climb profiles flown by four research pilots. Guidance was displayed to the pilots by means of a horizontal and vertical instrument landing system (ILS) type needle. The guidance scheme driving these needles was a function of a reference altitude, pitch attitude, and angle of attack for the horizontal needle, and a function of crosstrack error, crosstrack rate, and bank angle for the vertical needle. Differences in Mach, flightpath angle, altitude, and inertial azimuth of a projected launch point between the reference trajectory and the pilot-flown trajectory were documented. Of the five test cases flown-nominal, wind shear, tailwind, initial altitude and crosstrack offset, and thrust multiplier (-3-percent reduced net thrust) - only the thrust multiplier case generated significant deviations from the reference trajectory. These deviations were caused by the reduced energy state of the RLV. The pitch axis handling qualities during the maneuver generally were rated level 1 for the level acceleration, and level 2 for the pullup and ballistic portions of the maneuver. The roll axis generally was rated level 1 for all phases of the maneuver. Suggestions for improving the pilot displays include a pitch pullup cue, which would allow pilots to anticipate when the pullup begins, and a launch cue, which would allow pilots to minimize errors while establishing a steady-state condition at launch. 
At the conditions of the projected expendable launch vehicle (ELV) launch for each run, a rocket burn was applied to transfer the ELV to a desired operational orbit. Differences between the transfer orbit resulting from a given run and the transfer orbit resulting from a launch at the reference trajectory launch flight condition were calculated. These differences form a basis for bounding the sizing of the second-stage ELV design. For the thrust multiplier case, the most sensitive of the test cases investigated, the ELV launch energy was too low for the ELV to reach the operational orbit radius. For the remaining test cases, the errors in the ELV launch condition were small enough to provide a transfer orbit to the geocentric radius of the operational orbit for the payload. The most sensitive and critical RLV parameters at the ELV launch were inertial flightpath angle and inertial azimuth.

\section{REFERENCES}

1. Defense Advanced Research Projects Agency, Responsive Access, Small Cargo, \& Affordable Launch (RASCAL) Demonstration Program, Phase I, Program Solicitation 02-02, Dec. 10, 2001.

2. Plattner, C. M., "Space Training Flights in NF-104A Near," Aviation Week \& Space Technology, August 9, 1965, pp. 80-85.

3. Holleman, Euclid C., and Elmor J. Adkins, "Contributions of the X-15 Program to Lifting Entry Technology," Journal of Aircraft, vol. 1, no. 6, Nov.-Dec. 1964, pp. 360-366.

4. Fischel, Jack, and Lannie D. Webb, Flight-Informational Sensors, Display, and Space Control of the X-15 Airplane for Atmospheric and Near-Space Flight Missions, NASA TN D-2407, Aug. 1964.

5. Holleman, Euclid C., Piloting Performance During the Boost of the X-15 Airplane to High Altitude, NASA TN D-2289, April 1964.

6. Jarvis, Calvin R., and Elmor J. Adkins, Operational Experience With X-15 Reaction Controls, NASA TM X-56002, April 21, 1964.

7. Jarvis, Calvin R., and Wilton P. Lock, Operational Experience With the X-15 Reaction Control and Reaction Augmentation Systems, NASA TN D-2864, June 1965.

8. Henneberry, Hugh M., and Christopher A. Snyder, Analysis of Gas Turbine Engines Using Water and Oxygen Injection to Achieve High Mach Numbers and High Thrust, NASA TM 106270, July 1993.

9. Vallado, David A., and Wayne D. McClain, Fundamentals of Astrodynamics and Applications, Space Technology Series, Wiley J. Larson, ed., The McGraw-Hill Companies, Inc., 1997.

10. Wertz, James R., and Wiley J. Larson, eds., Space Mission Analysis and Design, Third Edition, Space Technology Series, Microcosm Press and Kluwer Academic Publishers, 1999.

11. Cooper, George E., and Robert P. Harper, Jr., The Use of Pilot Rating in the Evaluation of Aircraft Handling Qualities, NASA TN D-5153, April 1969.

12. Flying Qualities of Piloted Vehicles, U. S. Department of Defense, MIL-STD 1797, March 31, 1987. 


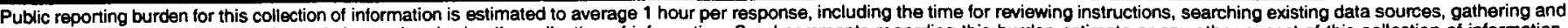

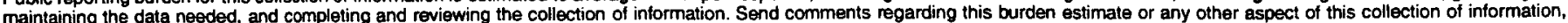

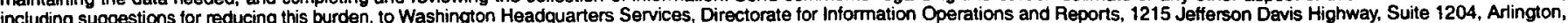
including suggestions tor reducing this burden, to Washington Headquarters Services, Directorate for Information Operations and
VA 22202-4302, and to the Office of Management and Budget, Paperwork Reduction Project (0704-0188), Washington, DC 20503.

\begin{tabular}{|l|l|l|}
\hline 1. AGENCY USE ONLY (Leave blank) & $\begin{array}{l}\text { 2. REPORT DATE } \\
\text { September 2003 }\end{array}$ & $\begin{array}{l}\text { 3. REPORT TYPE AND DATES COVERED } \\
\text { Technical Memorandum }\end{array}$ \\
\hline
\end{tabular}

4. TITLE AND SUBTITLE 5. FUNDING NUMBERS

Launch Condition Deviations of Reusable Launch Vehicle Simulations in

Exo-Atmospheric Zoom Climbs

6. AUTHOR(S)

Peter H. Urschel and Timothy H. Cox

7. PERFORMING ORGANIZATION NAME(S) AND ADDRESS(ES)

NASA Dryden Flight Research Center

P.O. Box 273

PERFORMING ORGA
REPORT NUMBER

Edwards, California 93523-0273

H-2533

9. SPONSORING/MONITORING AGENCY NAME(S) AND ADDRESS(ES)

National Aeronautics and Space Administration

Washington, DC 20546-0001

710-85-14-SE-47-00-DVI

10. SPONSORING/MONITORING

AGENCY REPORT NUMBER

NASA/TM-2003-212023

11. SUPPLEMENTARY NOTES

Also presented at the AIAA Atmospheric Flight Mechanics Conference and Exhibit, Aug. 11-14, 2003,

Austin, TX.

12a. DISTRIBUTIONAVAILABILITY STATEMENT

12b. DISTRIBUTION CODE

Unclassified-Unlimited

Subject Category 15

This report is available at http://www.dfrc.nasa.gov/DTRS/

13. ABSTRACT (Maximum 200 words)

The Defense Advanced Research Projects Agency has proposed a two-stage system to deliver a small payload to orbit. The proposal calls for an airplane to perform an exo-atmospheric zoom climb maneuver, from which a second-stage rocket is launched carrying the payload into orbit. The NASA Dryden Flight Research Center has conducted an in-house generic simulation study to determine how accurately a human-piloted airplane can deliver a second-stage rocket to a desired exo-atmospheric launch condition. A high-performance, fighter-type, fixed-base, real-time, pilot-in-the-loop airplane simulation has been modified to perform exoatmospheric zoom climb maneuvers. Four research pilots tracked a reference trajectory in the presence of winds, initial offsets, and degraded engine thrust to a second-stage launch condition. These launch conditions have been compared to the reference launch condition to characterize the expected deviation. At each launch condition, a speed change was applied to the second-stage rocket to insert the payload onto a transfer orbit to the desired operational orbit. The most sensitive of the test cases was the degraded thrust case, yielding secondstage launch energies that were too low to achieve the radius of the desired operational orbit. The handling qualities of the airplane, as a first-stage vehicle, have also been investigated.

\section{SUBJECT TERMS}

Exo-atmospheric zoom climb maneuver, Expendable launch vehicle,

Pilot-in-the-loop simulation, Reusable launch vehicle, Transfer orbit

17. SECURITY CLASSIFICATION
OF REPORT
Unclassified

NSN 7540-01-280-5500

18. SECURITY CLASSIFICATION
OF THIS PAGE
Unclassified
OF THIS PAGE
Unclassified

19. SECURITY CLASSIFICATION
OF ABSTRACT
Unclassified

\section{NUMBER OF PAGES} 39

16. PRICE CODE

20. LIMITATION OF ABSTRACT

Unlimited

Standard Form 298 (Rev. 2-89) Preacribed by ANSI Str. Z399-18 298-102 